\title{
Supervising Financial Regulators
}

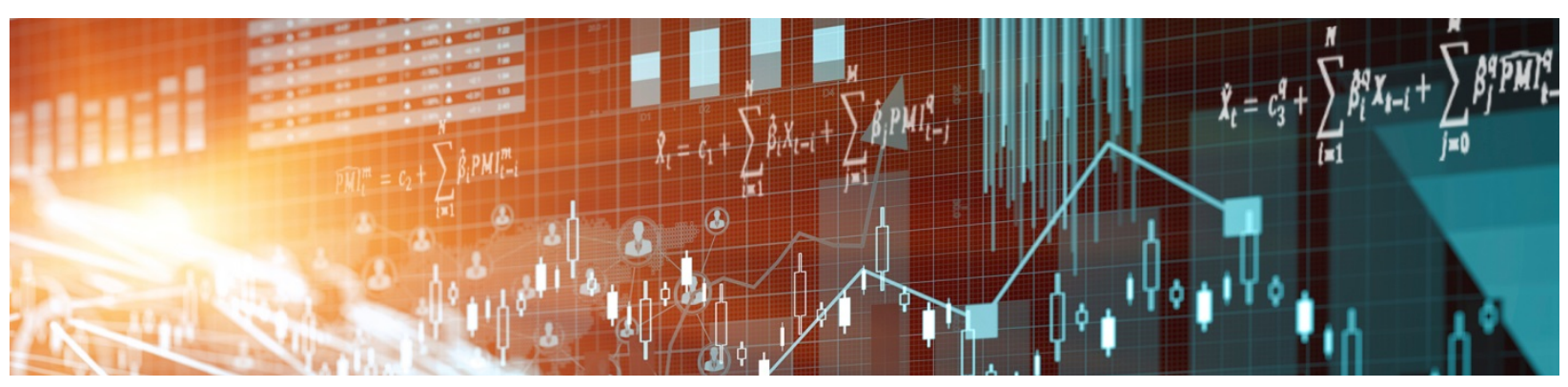

by Josef Schroth 
Bank of Canada Staff Working Paper 2016-52

November 2016

\title{
Supervising Financial Regulators
}

\author{
by \\ Josef Schroth \\ Financial Stability Department \\ Bank of Canada \\ Ottawa, Ontario, Canada K1A 0G9 \\ jschroth@bankofcanada.ca
}




\section{Acknowledgements}

For helpful comments and suggestions I am grateful to Jason Allen, Thibaut Duprey, Piero Gottardi, Florian Heider, Christian Hellwig, Hugo Hopenhayn, Luc Laeven, James MacGee, Robert Marquez, David Martinez-Miera, Ctirad Slavik, Eric Stephens,

Francesco Trebbi, Sergio Vicente, Larry Wall, Pierre-Olivier Weill and Stanley Winer. 


\begin{abstract}
How much discretion should local financial regulators in a banking union have in accommodating local credit demand? I analyze this question in an economy where local regulators privately observe expected output from high lending. They do not fully internalize default costs from high lending since deposit insurance cannot be priced fairly. Still, output net of default costs across the banking union is highest when local regulators are rewarded rather than punished. Regulators with lower current lending receive more discretion to allow higher lending in the future, but regulators with higher current lending may not experience any limit to their discretion.
\end{abstract}

Bank topics: Credit and credit aggregates; Financial stability; Financial systems regulation and policies; Regional economic developments

JEL codes: E44; G28; H7

\title{
Résumé
}

Quelle latitude les autorités prudentielles nationales devraient avoir dans une union bancaire pour répondre à la demande de crédit sur leur territoire? Pour analyser cette question, nous utilisons un modèle dans lequel les autorités prudentielles nationales sont seules en mesure d'observer le rendement attendu de la forte activité des prêteurs. Puisque l'assurance dépôt ne peut être tarifée de façon équitable, les autorités ne supportent pas l'intégralité des coûts de défaillance associés à la forte activité des prêteurs. Pour autant, le rendement net obtenu au sein de l'union bancaire, déduction faite des coûts de défaillance, est au plus haut quand l'autorité supranationale tend davantage à récompenser les autorités prudentielles qu'à les pénaliser. Les autorités prudentielles qui réduisent l'activité des prêteurs se voient donner plus de latitude afin de favoriser une hausse des volumes du crédit. Dans les territoires où l'activité des prêteurs s'accroît, les autorités prudentielles pourraient toutefois ne pas être soumises à des restrictions dans l'exercice de leur discrétion.

Sujets : Crédit et agrégats du crédit; Stabilité financière; Réglementation et politiques relatives au système financier; Évolution économique régionale

Codes JEL : E44; G28; H7 


\section{Non-Technical Summary}

Should local policy makers have discretion to accommodate local credit demand? I address this question in the context of an economy in which the cost of defaults is shared via a central deposit insurance fund. A moral hazard problem arises since local financial regulators in such a banking union may have incentives to overstate the social value of supporting local lending when the cost of defaults is being shared. This paper shows how coordinating lending across a banking union can help its members to internalize more of the costs they impose on a central deposit insurance fund. Specifically, while local financial regulators do not mind free-riding on others, they have concerns about free-riding by other local regulators. The paper then analyzes the trade-off between tightening lending coordination across the banking union and lowering lending discretion of local regulators that experienced greater defaults in the past. This trade-off has implications, for example, for whether a local financial regulator that has overseen a local lending boom should be allowed to rely on the deposit insurance fund to resolve a subsequent local financial crisis.

It is shown that optimal central supervision emphasizes rewards over punishments when providing incentives to local regulators. On the one hand, a local regulator that accommodated local credit demand to a lesser degree becomes a "deposit insurance fund creditor" and always enjoys higher discretion to accommodate in the future. On the other hand, a local regulator that accommodated local credit demand to a greater degree becomes a "deposit insurance fund debtor" and may not face a decrease in its discretion in the future at all. Instead, a debtor regulator would face retaliatory accommodation by the creditor. It is shown that retaliatory accommodation aligns incentives in a way similar to local fiscal backstops but does not put any demands on local fiscal capacity. 


\section{Introduction}

The Italian financial crisis has been more persistent than the 2007-2009 US financial crisis in part due to European Union restrictions on bailouts. In general, should a financial regulator that oversees a high volume of borrower defaults face reduced discretion to support lending in the future? I address this question in the context of a banking union in which the cost of defaults is shared via a deposit insurance fund. In particular, local financial regulators in a banking union may have incentives to overstate the social value of supporting local lending when the cost of defaults is being shared. ${ }^{1}$ A local financial regulator can support local lending by, for example, not leaning against a lending boom or by regulatory forbearance and bailouts during a financial crisis. ${ }^{2}$

In this paper, I study how coordinating lending across a banking union can help its members to internalize more of the costs they impose on a central deposit insurance fund. I analyze the trade-off between adjusting lending coordination across the banking union and lowering lending discretion of members that experienced greater defaults in the past. This trade-off has implications, for example, for whether a banking union member that experienced a local lending boom should be allowed to rely on the deposit insurance fund to resolve a subsequent local financial crisis.

I build a model of a banking union in which bank lending to firms is funded with

\footnotetext{
${ }^{1}$ Such incentive problems are being discussed in the context of plans to create a banking union in the European Union (ASC, 2012; Hellwig, 2014). In the case of the United States, Agarwal, Lucca, Seru, and Trebbi (2014) find that state regulators enjoy some discretion in affecting local lending, while the cost of state regulatory leniency is partially borne by the US federal deposit insurance fund.

${ }^{2}$ During the US mortgage boom, regulators allowed lower lending standards in the face of strong demand by borrowers (Dell'Ariccia et al., 2012). During the 2007-2009 US financial crisis, some banks enjoyed regulatory forbearance (Huizinga and Laeven, 2012) as well as extended coverage of the deposit insurance scheme (Demirgüç-Kunt et al., 2015), possibly supporting lending by reducing the pressure on those banks to reduce the size of their balance sheets. Schularick and Taylor (2012) find that financial crises are more likely when preceded by lending booms. However, not all lending booms end in a financial crisis (Gorton and Ordoñez, 2016) and it is difficult to predict which lending booms will (Reinhart and Rogoff, 2009). My analysis abstracts from economic links between crisis and non-crisis times and, instead, focuses on the incentives of local regulators to excessively support local lending by free-riding on the deposit insurance fund in either episode.
} 
insured deposits. There are two types of firms in each region of the banking union. I assume that deposit insurance can be priced to be actuarially fair in the case of deposits that fund lending to firms with verifiable cash flows. I also assume that such firms are mobile across the banking union such that deposits that fund loans to them carry the same insurance fund contribution in every region of the banking union. Local financial regulators can choose to allow local lending to firms with non-verifiable cash flows, or "leniency." The price of insurance of deposits that fund loans to this type of firm is assumed to be lower than actuarially fair. As a result, local leniency imposes a net cost on the economy-wide deposit insurance fund and creates a "free-riding" motive.

I assume that local output gains from local leniency depend on the stochastic state of the local economy that is privately observed by the respective local regulator. This informational asymmetry creates a tension between the objective of allowing leniency wherever it leads to sufficient output gains and the free-riding motive. However, while local financial regulators do not mind free-riding on others, they have concerns about free-riding by other local regulators. I explore how such concerns can be used to relieve some of the tensions created by asymmetric information.

I show that optimal supervision emphasizes rewards over punishments when providing incentives to local regulators. On the one hand, a local regulator exercising relatively less leniency becomes a "deposit insurance fund creditor" and always enjoys higher discretion in exercising leniency in the future. On the other hand, a local regulator that exercises relatively more leniency becomes a "deposit insurance fund debtor" and may not face a decrease in its discretion in the future at all.

Optimal supervision finds it costly to restrict discretion of a debtor over time and instead tightens lending coordination across the banking union by introducing statecontingent excessive creditor leniency. Specifically, when a debtor (again) reports a relatively higher need for local leniency, then, and only then, is the creditor allowed to 
increase leniency up to the point where borrowers with negative present value projects are funded in the creditor region. Such excessive creditor leniency is an indirect "side payment," via the deposit insurance fund, from the debtor to the creditor. This payment plays the role of exactly offsetting the effect of higher creditor discretion on both debtor and creditor incentives to report local economic conditions. As a result, there is no further need to restrict discretion of the debtor region.

Because of the emphasis of rewards over punishments, expected leniency across local regulators may increase in the future whenever actual leniency differed across the banking union in the past. A different regulatory stance across regions may thus lead to larger expected losses for the central deposit insurance fund in the future. This result holds even though local economic conditions are assumed to be independent over time and across regions. In that sense, disagreements over policy may lower financial stability in the future in the banking union.

The trade-off faced by optimal supervision is between restricting future discretion of local regulators that are relatively more lenient today and allowing future statecontingent excessive leniency of regulators that are relatively less lenient today. I show that the latter is preferred as long as the average output gain from leniency is not too low. I assume this condition holds in my two-period benchmark model. I also extend my model to an infinite horizon where the condition typically does not hold. The trade-off becomes more gradual with an infinite horizon but the qualitative insights are similar. It can be optimal to reduce debtor discretion somewhat and, at the same time, also to allow state-contingent excessive leniency of creditors. The emphasis on rewards over punishments is still present, however, as creditor discretion increases quickly while debtor discretion decreases slowly over time.

I also consider a direct side-payment technology in the form of local fiscal backstops. For example, one could think about a costly technology that makes it feasible to tax 
local firms with non-verifiable cash flows. I show that the indirect technology, which works via the deposit insurance fund, dominates the direct technology when local fiscal capacity is low; i.e., whenever local taxation is more distorting than some threshold. The extension thus shows that, unless fiscal capacity is high, optimal supervision has no need for fiscal backstops.

\subsection{Related literature}

Carletti, Dell'Ariccia, and Marquez (2015) also consider supervision of biased local financial regulators. Their analysis focuses on moral hazard of local regulators with respect to the collection of information, while I assume that local regulators possess a given amount of private information. They uncover a novel channel that breaks the monotonically increasing relationship between central supervisor regulatory standards and bank lending standards. Another difference from my paper is that they take the bias of local regulators as exogenous while I explicitly endogenize regulator bias as being due to externalities that local regulators impose on each other. Thus, in my model there is a benefit of linking, across local regulators, any supervision imposed on local regulators. This focus generates important novel dynamic implications for regulation. ${ }^{3}$ Holthausen and Rønde (2004) and Colliard (2014) study economies with privately informed and exogenously biased local regulators, respectively (see also Agur, 2013). These papers, in addition, allow for financial institutions to react to changes in regulatory stances explicitly, while financial institutions in my model are mere conduits. Zoican and Gornicka (2015) study the case of a supervisor of local financial regulators

\footnotetext{
${ }^{3}$ Linking actions within the period, and not only over time, can strengthen incentives in many different economic environments. Roberts (1985) and Goltsman and Pavlov (2014) show, in a static context, how firms facing oligopolistic competition can partially overcome inefficiencies due to asymmetric information about production costs by linking output within the period. Santoro (2015) studies optimal fiscal policy in a monetary union in a static model with two-sided private information and limited commitment. His model extends the model in Chari and Kehoe (2007) by allowing for private information, and adds to the analysis in Sanguinetti and Tommasi (2004) by allowing for limited commitment.
} 
who faces a time-inconsistency problem and may be too lenient ex-post in a way that distorts incentives of financial institutions toward more risk-taking. Time inconsistency in Carletti et al. (2015) implies that a supervisor may be too tough ex-post in a way that distorts incentives of local regulators toward less information collection. As I abstract from bank risk-taking and local regulator information collection, these sources of time inconsistency are not present in my model. Foarta (2015) focuses on political economy frictions and shows that assistance for a country facing financial sector difficulties must be designed with problems of local governance in mind. She shows that assistance for a country should be coordinated with both tighter fiscal rules and improved electoral accountability.

Foarta (2014) studies supervision of a single local regulator in a delegation problem similar to the one studied in Amador et al. (2006). In her model, dynamics-in the form of time-varying, rather than static as in Amador et al. (2006), policy cutoffs—can arise when a local regulator can issue non-contingent debt subject to borrowing constraints. When a local regulator incurs more debt in the model in Foarta (2014), then it trades higher discretion today against reduced discretion in the future. Instead, in my model, state-contingent excessive leniency arises after certain histories to lower the need to limit discretion of local regulators that have become more "indebted" to the deposit insurance fund.

\section{Model}

There are two time periods, $t=1,2$, and two economic regions $j=1,2$, with a local financial regulator each, and a consumption good. In each region, there is a credit demand shock $\theta_{j, t}$ that takes values $\theta_{L}$ or $\theta_{H}$ with equal probability in each period. Let the mean and variance of the shock be denoted by $\mu$ and $\sigma^{2}$, respectively. It is assumed 
that $1 / 2<\theta_{L}<1<\theta_{H}$ and that $\mu<1$. There is a central supervisor operating a deposit insurance fund. In each region and in each period, there is a measure $M>0$ of transparent firms, a measure 1 of opaque firms, and a measure $N>M+1$ of banks and depositors, respectively. Depositors are endowed with one unit of the good that they are willing to lend to any bank, but only if they receive repayment with certainty. Banks and firms are protected by limited liability.

Firms have no internal funds and can invest only when borrowing from a bank. Transparent firms have access to a project that transforms one unit of the good into either $2(1+r)$ or zero units of the good, with equal probability. I assume that $r>0$. Opaque firm $i \in[0,1]$ in region $j=1,2$ has access to a project that transforms one unit of the good into either $1+z^{i}$ or zero units of the good, with equal probability. I assume that $z^{i}$ is continuously distributed on $[0, \infty)$ with region-specific mean $\theta_{j, t} \cdot{ }^{4}$ I assume that $z^{i}$ cannot be observed or verified by anyone other than opaque firm $i$ such that, in particular, a bank cannot ask for repayment larger than one from an opaque firm.

A bank that receives a repayment of less than 1 is considered insolvent. I assume that insolvent banks cease to monitor firms such that a firm loses its entire cash flow when its bank becomes insolvent. ${ }^{5}$ Banks have no internal funds and thus rely on deposits exclusively. Banks that engage in lending need to acquire insurance for all deposits since they face a strictly positive probability of insolvency.

The central supervisor requires solvent banks to pay $x_{t}$ units of the consumption good into the deposit insurance fund per unit of lending to transparent firms. Note

\footnotetext{
${ }^{4}$ The parameter $\theta_{j, t}$ determines the output gain from extending bank lending to opaque firms. The assumption $\operatorname{Prob}\left(\theta_{j, t}=\theta_{H}\right)=1 / 2$ implies that this gain is higher than average half the time. Gorton and Ordoñez (2016) find, in a sample of developed and emerging economies, that lending is higher than average roughly half the time.

${ }^{5}$ In the model, firm cash flows are already zero when firms cannot repay the bank. Alternatively, one could assume that any non-zero firm cash flows are on the bank balance sheet at the time of bank insolvency such that they are being received by the deposit insurance fund. The assumption makes sure that banks' monitoring role cannot involve helping firms to defraud the deposit insurance fund.
} 
that deposit insurance fund contributions must be uniform across the banking union since banks and transparent firms are mobile across regions. ${ }^{6}$ The supervisor does not charge fund contributions per unit of lending to opaque firms as this would lead to bank insolvency in states of the world where opaque firm cash flows are non-zero. Since banks are competitive, their profit is always zero and they are indifferent with regard to lending to transparent firms at gross rate $1+x_{t}$, lending to opaque firms at gross rate 1 , or not lending at all.

Let $\ell_{j, t} \in[0,1]$ denote lending to opaque firms, or leniency, in region $j$ in period $t .^{7} \mathrm{I}$ assume that $2 r M>1$ to ensure that the deposit insurance fund has "deep pockets" in the sense that contributions, which are at most $(1+2 r) M$, can always be chosen to match withdrawals, which are at most $M+1$. I assume that the deposit insurance fund must break even at each point in time. The deposit insurance fund breaks even whenever expected deposit insurance fund distributions across the banking union equal expected contributions as follows:

$$
M+\frac{1}{2}\left(\ell_{1, t}+\ell_{2, t}\right)=M x_{t}
$$

Equation (1) shows that deposit fund contributions levied on lending to transparent firms in each region depend on lending to opaque firms in both regions, $x_{t}=1+$ $\left(\ell_{1, t}+\ell_{2, t}\right) / 2 M$.

Alternatively, it could be assumed that the deposit insurance fund breaks even only at the end of the second period and borrows in the first period to pay for distributions in the first period. The timing of contributions to the deposit insurance fund is not crucial as long as the net present value of contributions passed on to firms is the same for each

\footnotetext{
${ }^{6}$ One could, however, think of different risk classes of transparent firms with different probabilities of zero cash flow but same expected cash flow. Then banks lending to riskier transparent firms would pay larger deposit insurance fund contributions.

${ }^{7}$ From the viewpoint of the individual opaque firm, $\ell_{j, t}$ is the probability that its request for a bank loan of unit size is granted. For example, this could be achieved by making loan approval dependent on certain observable random characteristics of the opaque firm.
} 
type of firm. Specifically, the model is consistent with a deposit insurance fund that carries a low balance to meet its "microprudential role" of insuring deposits that fund transparent firms while meeting its "macroprudential role" of insuring opaque lending by raising contributions ex-post.

\subsection{Objective of central supervisor}

I assume that the central supervisor has the objective of maximizing expected firm profit across the banking union. Expected firm profits in region $j=1,2$ in period $t=1,2$ are given by the following equation:

$$
\frac{1}{2}\left(2(1+r)-\left(1+x_{t}\right)\right) M+\frac{1}{2}\left(1+\theta_{j, t}-1\right) \ell_{j, t}=\frac{1}{2} \theta_{j, t} \ell_{j, t}-\frac{1}{4}\left(\ell_{1, t}+\ell_{2, t}\right)+r M .
$$

Local leniency generates output of local opaque firms but also generates negative spillovers, affecting all transparent firms across the banking union, since lending to opaque firms is a burden to the deposit insurance fund on average. Let $\ell_{j}=\left\{\ell_{j, t}\left(\theta^{t}\right)\right\}_{\theta^{t} \in \Theta^{t}, t=1,2}$ denote a path for leniency in region $j$, where $\Theta=\left\{\theta_{L}, \theta_{H}\right\} \times\left\{\theta_{L}, \theta_{H}\right\}$, and let $\theta^{t}$ denote the history of realizations of shocks at time $t=1,2$ such that $\theta^{t} \in \Theta^{t}$. I assume that local regulators have the objective of maximizing expected local firm profits. Using equation (2), their welfare criteria, up to a constant, are then given by

$$
\begin{aligned}
& \sum_{t=1,2} \delta^{t-1}\left(\frac{1}{2}\right)^{2 t} \sum_{\theta^{t} \in \Theta^{t}}\left[\left(\theta_{1, t}-\frac{1}{2}\right) \ell_{1, t}\left(\theta^{t}\right)-\frac{1}{2} \ell_{2, t}\left(\theta^{t}\right)\right], \\
& \sum_{t=1,2} \delta^{t-1}\left(\frac{1}{2}\right)^{2 t} \sum_{\theta^{t} \in \Theta^{t}}\left[\left(\theta_{2, t}-\frac{1}{2}\right) \ell_{2, t}\left(\theta^{t}\right)-\frac{1}{2} \ell_{1, t}\left(\theta^{t}\right)\right],
\end{aligned}
$$


where $\delta>0$ is a discount factor. The central supervisor's welfare criterion is the sum of individual regions' welfare criteria as follows:

$$
\Omega \equiv \sum_{t=1,2} \delta^{t-1}\left(\frac{1}{2}\right)^{2 t} \sum_{\theta^{t} \in \Theta^{t}}\left[\left(\theta_{1, t}-1\right) \ell_{1, t}\left(\theta^{t}\right)+\left(\theta_{2, t}-1\right) \ell_{2, t}\left(\theta^{t}\right)\right]
$$

Increasing leniency by one (marginal) unit in region $j$ reduces transparent firm profits, conditional on generating a non-zero cash flow, by half a unit in each region via increased contributions to the deposit insurance fund. The local net benefit of leniency for local regulator $j$ in period $t$ is therefore $\frac{1}{2}\left(\theta_{j, t}-1 / 2\right)$ (see equation (3)), while the economy-wide net benefit is only $\frac{1}{2}\left(\theta_{j, t}-1\right)$ (see equation (4)).

\subsection{First-best allocation}

The first-best is defined at the paths for leniency that maximize joint welfare; i.e., the central supervisor's welfare criterion $\Omega$. Lemma 1 shows that first-best leniency depends only on respective local shocks and is thus independent over time and across regions.

Lemma 1. First-best leniency in region $j$ at time $t$ is given as follows:

$$
\ell_{j, t}^{F B}\left(\theta^{t}\right)=\ell^{F B}\left(\theta_{j, t}\right)=\left\{\begin{array}{ll}
0, & \text { if } \theta_{j, t}=\theta_{L} ; \\
1, & \text { if } \theta_{j, t}=\theta_{H},
\end{array} \quad \theta^{t} \in \Theta^{t}, t=1,2, j=1,2,\right.
$$

and yields joint welfare of $\Omega^{F B}=(1+\delta)\left(\theta_{H}-1\right)$.

Proof. From the expression of $\Omega$ in equation (4), it can be seen that leniency in region $j$ should be as low as possible whenever $\theta_{j, t}<1$, and as high as possible whenever $\theta_{j, t}>1$. Recall that $\theta_{L}<1<\theta_{H}$.

Corollary 1. First-best leniency is not incentive-compatible. 
Proof. The economy-wide net benefit of leniency in region $j$ by equation (4) is given by $\theta_{j, t}-1$, which is positive only for $\theta_{j, t}=\theta_{H}$. However, local regulator $j$ 's local net benefit of leniency, according to equation (3), is given by $\theta_{j, t}-1 / 2$, which is always positive. A local regulator thus has an incentive to always claim having observed the high shock.

When all else is constant, a local regulator prefers its own local leniency to be as high as possible irrespective of the local shock. In section 3, coordination of leniency will be useful precisely because it removes the notion of "all else constant."

\section{Analysis of the Model}

This section characterizes the paths for leniency that maximize the central supervisor's objective subject to incentivizing local regulators to truthfully report local shocks. Each period, both local regulators report respective local shocks at the same time.

\subsection{Static case without coordination}

In this subsection, I study the case in which leniency in region $j$ can depend only on the current local shock such that $\ell_{j, t}\left(\theta^{t}\right)=\ell_{j, t}\left(\theta_{j, t}\right)$. Leniency is, by assumption, not coordinated across regions of the banking union in this case. However, local regulator $j$ then reports the shock that yields it the highest degree of leniency (recall the discussion following Corollary 1). Leniency is then constant at some $\bar{\ell} \in[0,1] .{ }^{8}$ Expected welfare in region $j$ is given by $(\mu-1) \bar{\ell}$ in each period. Since $\mu<1$, the central supervisor sets $\bar{\ell}$ to zero such that lending to opaque firms is zero at all times and in every region. For the remainder of this paper, it is assumed that each local regulator must enjoy expected

\footnotetext{
${ }^{8} \bar{\ell}$ could also be interpreted as an upper bound on leniency (see Melumad and Shibano, 1991; Tanner, 2013; Amador and Bagwell, 2013).
} 
welfare of at least zero at the beginning of each period. In other words, each member of the banking union can, before observing its own shock, veto the use of insured deposits in the funding of loans to opaque firms.

Assumption 1 (individual rationality). At the beginning of each period, before shocks are observed, each local regulator must enjoy expected welfare of at least zero.

\subsection{Static case with coordination}

In this section, I study the case in which leniency in region $j$ can depend only on current shocks such that $\ell_{j, t}\left(\theta^{t}\right)=\ell_{j, t}\left(\theta_{1, t}, \theta_{2, t}\right)$. Leniency can potentially be coordinated across regions of the banking union in this case. Lemma 2 shows how leniency optimally depends on reported shocks in this case.

Lemma 2. Suppose leniency can depend only on current but not past shocks. Then, joint welfare is maximized by leniency given by

$$
\begin{aligned}
& \ell_{1, t}\left(\theta_{H}, \theta_{H}\right)=\ell_{2, t}\left(\theta_{H}, \theta_{H}\right)=1, \\
& \ell_{1, t}\left(\theta_{H}, \theta_{L}\right)=\ell_{2, t}\left(\theta_{L}, \theta_{H}\right)=\frac{1-\theta_{L}}{\theta_{L}}, \\
& \ell_{1, t}\left(\theta_{L}, \cdot\right)=\ell_{2, t}\left(\cdot, \theta_{L}\right)=0 .
\end{aligned}
$$

Proof. See Appendix A.1.

When both local regulators report the high shock then leniency is first-best across the banking union. However, leniency is coordinated in the sense that a high need for bank loans by opaque firms in a region is met only partially when the need for opaque lending is low in the respective other region. As a result, the discretion of local regulators to set leniency depending on the local shock is limited. Note that there is no excessive 
leniency, $\ell_{1, t}\left(\theta_{L}, \cdot\right)=\ell_{2, t}\left(\cdot, \theta_{L}\right)=0$, such that opaque firms never receive funding when their average productivity is low. It follows directly from Lemma 2 that period welfare for each local regulator $j=1,2$ is given by

$$
v_{0}=\frac{1}{4} \sum_{\theta_{1}, \theta_{2}}\left(\theta_{j, t}-1\right) \ell_{j, t}\left(\theta_{1, t}, \theta_{2, t}\right)=\frac{\theta_{H}-1}{4 \theta_{L}}
$$

which is strictly larger than period welfare of zero obtained in the static case without coordination (section 3.1). The reason for this improvement is that coordinating leniency within the period can relax incentive compatibility constraints.

Intuitively, a local regulator has a lower incentive to overstate the need for bank loans by local opaque firms whenever announcing a low need results in reducing loans to opaque firms in the respective other region. To see this, consider a local regulator with shock $\theta_{L}$ who reports $\theta_{H}$ instead. Such a local regulator now enjoys higher leniency, on average, which increases the local regulator's period welfare in expectation by

$$
\frac{1}{2}\left[\theta_{L}-\frac{1}{2}\right]+\frac{1}{2}\left[\theta_{L}-\frac{1}{2}\right] \frac{1-\theta_{L}}{\theta_{L}}=\frac{1}{2}\left(\theta_{L}-\frac{1}{2}\right) \frac{1}{\theta_{L}} .
$$

But leniency in the other region is now also higher, on average, which decreases the period welfare payoff by $\frac{1}{2} \frac{1}{2}\left(1-\frac{1-\theta_{L}}{\theta_{L}}\right)=\frac{1}{2}\left(\theta_{L}-\frac{1}{2}\right) \frac{1}{\theta_{L}}$. Thus, the local regulator cannot achieve a net increase in its period welfare by overstating its need for leniency. What keeps a local regulator from overstating its shock is the expected increase in the other local regulator's leniency and the associated increase in contributions to the deposit insurance fund. Local regulators cannot free ride on each other's contributions toward the deposit insurance fund if leniency is coordinated in this way. 


\subsection{Dynamic case with coordination}

The main focus of this paper is how leniency in each region depends on current as well as past shocks across the two regions in the banking union. Leniency can thus be coordinated within each period and local regulators can also transfer utility intertemporally. I use my model to study how within-period coordination changes when local regulators transfer utility intertemporally. Policy implications are discussed.

\subsubsection{Second period}

It is useful to first characterize the set of feasible second-period welfare pairs that can be delivered to local regulators. Let $v \in[0, \bar{v}]$ be second-period welfare to be delivered to local regulator $j=2$. The lower bound on $v$ is due to Assumption 1, and $\bar{v}$ will be defined below. For a given $v$, let $\ell_{j}\left(\theta_{1}, \theta_{2}\right)$ be leniency of local regulator $j=1,2$ when local regulator one reports shock $\theta_{1}$ and local regulator two reports shock $\theta_{2}$ in the second period. Local regulator two enjoys second-period welfare of at least $v$ whenever the following promise-keeping constraint holds:

$$
\frac{1}{4} \sum_{\left(\theta_{1}, \theta_{2}\right) \in \Theta}\left[\theta_{2} \ell_{2}\left(\theta_{1}, \theta_{2}\right)-\frac{1}{2} \ell_{1}\left(\theta_{1}, \theta_{2}\right)-\frac{1}{2} \ell_{2}\left(\theta_{1}, \theta_{2}\right)\right] \geq v
$$


Local regulators will report shocks truthfully whenever the following incentive compatibility constraints hold: ${ }^{9}$

$$
\begin{aligned}
& \frac{1}{2} \sum_{\theta_{2} \in\left\{\theta_{L}, \theta_{H}\right\}}\left[\theta_{L} \ell_{1}\left(\theta_{L}, \theta_{2}\right)\right.\left.-\frac{1}{2} \ell_{1}\left(\theta_{L}, \theta_{2}\right)-\frac{1}{2} \ell_{2}\left(\theta_{L}, \theta_{2}\right)\right] \\
& \geq \frac{1}{2} \sum_{\theta_{2} \in\left\{\theta_{L}, \theta_{H}\right\}}\left[\theta_{L} \ell_{1}\left(\theta_{H}, \theta_{2}\right)-\frac{1}{2} \ell_{1}\left(\theta_{H}, \theta_{2}\right)-\frac{1}{2} \ell_{2}\left(\theta_{H}, \theta_{2}\right)\right], \\
& \frac{1}{2} \sum_{\theta_{1} \in\left\{\theta_{L}, \theta_{H}\right\}}\left[\theta_{L} \ell_{2}\left(\theta_{1}, \theta_{L}\right)-\frac{1}{2} \ell_{1}\left(\theta_{1}, \theta_{L}\right)-\frac{1}{2} \ell_{2}\left(\theta_{1}, \theta_{L}\right)\right] \\
& \geq \frac{1}{2} \sum_{\theta_{1} \in\left\{\theta_{L}, \theta_{H}\right\}}\left[\theta_{L} \ell_{2}\left(\theta_{1}, \theta_{H}\right)-\frac{1}{2} \ell_{1}\left(\theta_{1}, \theta_{H}\right)-\frac{1}{2} \ell_{2}\left(\theta_{1}, \theta_{H}\right)\right] .
\end{aligned}
$$

Let $P(v)$ be the highest second-period welfare that can be delivered to local regulator one given the promise $v$ to local regulator two. That is, $P(v)$ is defined as

$$
P(v)=\max _{\left\{\ell_{j}\right\}_{j=1,2}} \frac{1}{4} \sum_{\left(\theta_{1}, \theta_{2}\right) \in \Theta}\left[\left(\theta_{1}-\frac{1}{2}\right) \ell_{1}\left(\theta_{1}, \theta_{2}\right)-\frac{1}{2} \ell_{2}\left(\theta_{1}, \theta_{2}\right)\right],
$$

subject to (6), (8), and (9). Then the graph of $P,\left\{\left(v_{1}, v_{2}\right): v_{2} \in[0, \bar{v}], v_{1}=P\left(v_{2}\right)\right\}$, is the Pareto frontier in period two. Note that $P(v)$ is decreasing by the promise-keeping constraint (6). I define $\bar{v}=P(0)$. In the case in which both local regulators enjoy the same second-period welfare, $P\left(v_{0}\right)=v_{0}$, the allocation is given by Lemma 2 and $v_{0}$ is given by equation (5). Depending on the parameters, there are two cases to consider for how leniency of local regulators is affected when $v \neq v_{0}$. Assumption 2 identifies

\footnotetext{
${ }^{9}$ When conditions (8) and (9) are satisfied, local regulators will have no incentive to understate shocks as long as the following monotonicity condition holds:

$$
\sum_{\theta_{2} \in\left\{\theta_{L}, \theta_{H}\right\}}\left[\ell_{1}\left(\theta_{H}, \theta_{2}\right)-\ell_{1}\left(\theta_{L}, \theta_{2}\right)\right] \geq 0 \text {, and } \sum_{\theta_{1} \in\left\{\theta_{L}, \theta_{H}\right\}}\left[\ell_{2}\left(\theta_{1}, \theta_{H}\right)-\ell_{2}\left(\theta_{1}, \theta_{L}\right)\right] \geq 0 .
$$

Condition (7) requires that the function $\ell_{j}$ increases in $\theta_{j}$ in expectation, for $j=1,2$. However, the condition is satisfied at an optimum and can be ignored.
} 
the relatively more interesting case in which leniency or discretion to exercise leniency depending on the local shock, or both, matter in the economy.

Assumption 2. Leniency or discretion matter in the sense that $\sigma>\sqrt{\mu(1-\mu)}$.

The condition in Assumption 2 holds if discretion matters in the sense of $\sigma$ being large, or if leniency matters in the sense of $\mu$ being large (see Figure 1). When neither matters, then the condition does not hold and the problem studied in this paper-the problem of how to allow local regulators to exercise discretion with respect to leniency-is not a very interesting one. Policy discussions about "leaning against the wind" and "counter-cyclical regulation" suggest that regulatory leniency should depend on economic and financial conditions. In particular the potential for tail events implies that the range of economic and financial conditions considered should not be too narrow-i.e., $\sigma$ should not be too small-in any discussion of financial regulation (Basel Committee on Banking Supervision, 2010). Discretion with respect to regulatory leniency in the form of regulatory forbearance also seems to play an important role in practice (Huizinga and Laeven, 2012). Assumption 2 is thus maintained throughout this section.

When $v \neq v_{0}$, the question arises as to how we can make one local regulator better off than the other along the Pareto frontier. Since local regulators are ex ante identical, it is sufficient to characterize the case $v<v_{0}$ (or equivalently $P(v)>v_{0}$ ) where local regulator one obtains relatively higher second-period welfare along the Pareto frontier. Lemma 3 shows how this is optimally achieved.

Lemma 3. Suppose $v<v_{0}$, such that local regulator one is better off along the Pareto frontier. Then, relative to the allocation at $v_{0}$,

1. $\ell_{1}\left(\theta_{H}, \theta_{L}\right)$ is strictly higher, 
2. $\ell_{2}\left(\theta_{L}, \theta_{H}\right)$ is unchanged for $3 \sigma-\mu \leq 0$, and strictly lower otherwise,

3. $\ell_{1}\left(\theta_{L}, \theta_{H}\right)$ is strictly higher; $\ell_{2}\left(\theta_{H}, \theta_{L}\right)$ remains unchanged at zero,

4. leniency is unchanged in the state in which both local regulators experience the same shock; specifically, $\ell_{1}\left(\theta_{L}, \theta_{L}\right)$ and $\ell_{2}\left(\theta_{L}, \theta_{L}\right)$ remain unchanged at zero, and $\ell_{1}\left(\theta_{H}, \theta_{H}\right)$ and $\ell_{1}\left(\theta_{H}, \theta_{H}\right)$ remain unchanged at 1 .

Proof. See Appendix A.1.

When $v<v_{0}$, then local regulator one is better off along the Pareto frontier. Lemma 3 shows how the allocation of leniency changes relative to the symmetric case $v=v_{0}$ characterized in Lemma 2. Specifically, local regulator one is made better off by allowing it increased discretion; i.e., $\ell_{1}\left(\theta_{H}, \theta_{L}\right)$ increases while $\ell_{1}\left(\theta_{H}, \theta_{H}\right)$ remains at 1 . If $3 \sigma-\mu \leq$ 0 (region B in Figure 1) then local regulator two is not required to reduce its discretion to exercise leniency, such that $\ell_{2}\left(\theta_{L}, \theta_{H}\right)$ is unchanged while $\ell_{2}\left(\theta_{H}, \theta_{H}\right)$ stays at the upper bound 1 . However, both the increased discretion for local regulator one and the fact that local regulator two may not be required to decrease its discretion work toward weakening incentives to report shocks truthfully. Incentives are maintained along the Pareto frontier via state-contingent leniency by local regulator one that is excessive in the sense of generating expected cash flows lower than borrowed funds at opaque firms. In particular, local regulator one exercises strictly positive leniency $\ell_{1}\left(\theta_{L}, \theta_{H}\right)$ in the state where only local regulator two experiences the high shock. Allowing $\ell_{1}\left(\theta_{L}, \theta_{H}\right)>0$ has the benefit of reducing the stress that discretion by both local regulators puts on incentive compatibility conditions. In particular, $\ell_{1}\left(\theta_{H}, \theta_{L}\right)$ and $\ell_{1}\left(\theta_{L}, \theta_{H}\right)$ increase by the same amount in $v$ such that the respective net effects on incentive conditions (8) and (9) are none. In contrast, $\ell_{1}\left(\theta_{L}, \theta_{L}\right)$ remains at zero, since leniency of local regulator one in this state contributes less to maintaining incentives. 


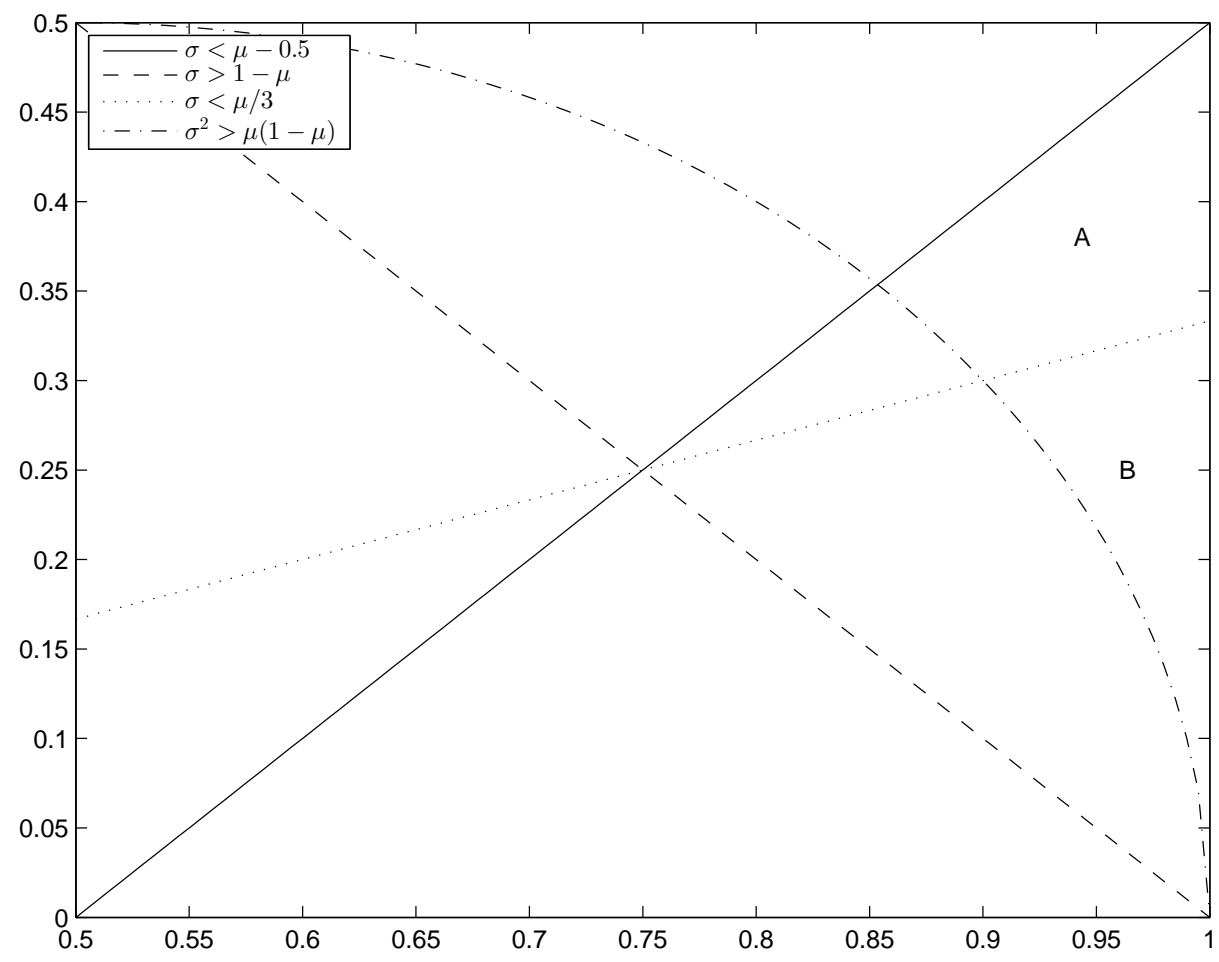

Figure 1: Restrictions on model parameters $\mu$ and $\sigma$ in $(\mu, \sigma)$ space. Parameter pairs in A or B satisfy all restrictions imposed by $\mu<1, \theta_{L}-\frac{1}{2}>0$, $\theta_{H}-1>0$, and Assumption 2. The line $\sigma=\frac{\mu}{3}$ divides the region of permissible parameter pairs into two subregions, A and B.

The use of state-contingent excessive leniency along the Pareto frontier reduces the need to decrease discretion of the local regulator with lower second-period welfare. Lemma 4 shows that, as a result, expected leniency may increase relative to the symmetric case $v=v_{0}$. Specifically, if $3 \sigma-\mu \leq 0$, a transfer of second-period welfare among local regulators is associated with higher expected leniency. An increase in expected leniency reduces financial stability in the banking union in the sense of increasing expected withdrawals from the deposit insurance fund.

Lemma 4. If $3 \sigma-\mu \leq 0$, then along the Pareto frontier expected leniency across local regulators is strictly higher when $v \neq v_{0}$ compared with the case $v=v_{0}$.

Proof. See Appendix A.1. 


\subsubsection{First period}

Local regulators can be assigned different second-period welfare levels, $v_{1}$ and $v_{2}$, in the first period in a way that encourages them to truthfully reveal the shocks they experience in the first period, as is standard in the risk-sharing literature. That is, second-period welfare can be made contingent on reports of shocks in the first period, $v_{j}: \Theta \rightarrow \mathbb{R}_{+}$. The Pareto frontier derived in the previous section allows us to express the set of feasible pairs of second-period welfare as

$$
\mathcal{P}=\left\{\left(v_{1}, v_{2}\right) \in \mathbb{R}_{+}^{2}: v_{1} \leq P\left(v_{2}\right)\right\}
$$

Let $\ell_{j}$ denote leniency of local regulator $j$ in the first period, $\ell_{j}: \Theta \rightarrow[0,1]$. The problem of a central supervisor of local regulators that wishes to maximize joint welfare of local regulators $\Omega$ is as follows:

$$
\max _{\left\{\ell_{j}, v_{j}\right\}_{j=1,2}} \frac{1}{4} \sum_{\left(\theta_{1}, \theta_{2}\right) \in \Theta}\left[\left(\theta_{1}-1\right) \ell_{1}\left(\theta_{1}, \theta_{2}\right)+\left(\theta_{2}-1\right) \ell_{2}\left(\theta_{1}, \theta_{2}\right)+\delta\left(v_{1}\left(\theta_{1}, \theta_{2}\right)+v_{2}\left(\theta_{1}, \theta_{2}\right)\right)\right],
$$

subject to incentive compatibility

$$
\begin{aligned}
& \frac{1}{2} \sum_{\theta_{2} \in\left\{\theta_{L}, \theta_{H}\right\}}\left[\theta_{L} \ell_{1}\left(\theta_{L}, \theta_{2}\right)\right.\left.-\frac{1}{2} \ell_{1}\left(\theta_{L}, \theta_{2}\right)-\frac{1}{2} \ell_{2}\left(\theta_{L}, \theta_{2}\right)+\delta v_{1}\left(\theta_{L}, \theta_{2}\right)\right] \\
& \geq \frac{1}{2} \sum_{\theta_{2} \in\left\{\theta_{L}, \theta_{H}\right\}}\left[\theta_{L} \ell_{1}\left(\theta_{H}, \theta_{2}\right)-\frac{1}{2} \ell_{1}\left(\theta_{H}, \theta_{2}\right)-\frac{1}{2} \ell_{2}\left(\theta_{H}, \theta_{2}\right)+\delta v_{1}\left(\theta_{H}, \theta_{2}\right)\right],
\end{aligned}
$$




$$
\begin{aligned}
\frac{1}{2} \sum_{\theta_{1} \in\left\{\theta_{L}, \theta_{H}\right\}}\left[\theta_{L} \ell_{2}\left(\theta_{1}, \theta_{L}\right)-\frac{1}{2} \ell_{1}\left(\theta_{1}, \theta_{L}\right)-\frac{1}{2} \ell_{2}\left(\theta_{1}, \theta_{L}\right)+\delta v_{2}\left(\theta_{1}, \theta_{L}\right)\right] \\
\geq \frac{1}{2} \sum_{\theta_{1} \in\left\{\theta_{L}, \theta_{H}\right\}}\left[\theta_{L} \ell_{2}\left(\theta_{1}, \theta_{H}\right)-\frac{1}{2} \ell_{1}\left(\theta_{1}, \theta_{H}\right)-\frac{1}{2} \ell_{2}\left(\theta_{1}, \theta_{H}\right)+\delta v_{2}\left(\theta_{1}, \theta_{H}\right)\right],
\end{aligned}
$$

and feasibility $\left(v_{1}\left(\theta_{1}, \theta_{2}\right), v_{2}\left(\theta_{1}, \theta_{2}\right)\right) \in \mathcal{P}$ for all $\left(\theta_{1}, \theta_{2}\right) \in \Theta$. Lemma 5 verifies that variation in second-period welfare is in fact used in the first period to make leniency more responsive to shocks in the first period.

Lemma 5. The solution to the central supervisor's problem has the following characteristics:

1. When local regulators experience the same shock in the first period, then both local regulators receive second-period welfare of $v_{0}$. First-period leniency is first-best, as in the allocation in Lemma 2.

2. When local regulators experience different shocks in the first period, then second-period welfare is varied along the Pareto frontier; i.e., $\theta_{i}<\theta_{j}$ implies $v_{i}>v_{j}=P\left(v_{i}\right)$. Firstperiod leniency is not first-best but local regulators enjoy more discretion compared with the allocation in Lemma 2.

Proof. See Appendix A.1.

When both local regulators experience the same shock, then optimal static leniency given by Lemma 2 already delivers the first-best. Variation in second-period welfare is not beneficial in this case, such that both local regulators receive second-period welfare of $v_{0}$. In the case in which local regulators experience different shocks, it is beneficial to vary second-period welfare in order to improve upon partial insurance provided by the allocation in Lemma 2. Together, Lemmas 3 and 5 yield the main result of the paper. Proposition 1 shows how current coordination of leniency across local regulators depends on history. 
Proposition 1. Let $\theta_{1}, \theta_{2}$ be shocks in the first period. If $\theta_{1}=\theta_{2}$, then optimal leniency in the second period is as given in Lemma 2. If $\theta_{1} \neq \theta_{2}$, such that $\theta_{i}<\theta_{j}$, then in the second period, compared with the case $\theta_{1}=\theta_{2}$,

1. local regulator i enjoys strictly higher discretion,

2. local regulator $j$ 's discretion is unchanged if $3 \sigma-\mu \leq 0$ and strictly lower otherwise,

3. local regulator i engages in state-contingent excessive leniency; specifically, leniency of local regulator $i$ is strictly positive in the state of the world where only local regulator $j$ experiences a high shock, but zero in the state where both experience the low shock.

Proof. We know from Lemma 5 that second-period welfare is $v_{1}=v_{2}=v_{0}$ whenever $\theta_{1}=\theta_{2}$ in the first period. However, second-period leniency is then given in Lemma 2. We know from Lemma 5 that $\theta_{i}<\theta_{j}$ implies second-period welfare of $v_{i}>v_{j}$ along the Pareto frontier. The implications for second-period leniency then follow from Lemma 3.

Inefficiencies due to a past disagreement about the need for leniency-i.e., costly movements along the Pareto frontier away from symmetric second-period welfare-can be mitigated by adjusting coordination of leniency. Coordination is adjusted to expand outward the set of feasible second-period welfare pairs and hence to make intertemporal utility transfers cheaper. This is why intertemporal and intratemporal margins for incentive provision should interact at an optimum.

A local regulator is rewarded for exercising less leniency in the first period by granting it more discretion over regulatory leniency in the second period. Period two incentive compatibility is maintained by allowing that local regulator to discipline the respective other local regulator via state-contingent excessive leniency. An alternative way of maintaining incentives would be to strongly reduce discretion of the regulator 
that is more "indebted" to the deposit insurance fund. This turns out to be not optimal, however, whenever Assumption 2 holds; i.e., whenever average output generated from leniency is not too low. ${ }^{10}$

Hence, a local regulator oversees delivery of its higher second-period welfare by disciplining the respective other local regulator. In that sense, excessive leniency is not a direct punishment of the other local regulator for its past behavior, but rather a means of facilitating intertemporal utility transfers. The model thus gives an example of how short-lived institutions (i.e., one local regulator disciplining the other) can arise endogenously after certain histories within a long-lived relationship (i.e., the ex ante optimal supervisory arrangement).

\subsection{Discussion of policy implications}

Optimal supervision of local regulators focuses on rewarding lower leniency in the past with higher discretion in the future. Indeed, higher leniency in the past may not be punished at all by lower discretion in the future. The supervisor makes this focus on rewarding good behavior rather than punishing bad behavior incentive-compatible by rewarding not only with higher discretion but also with state-contingent excessive leniency.

A banking union may be able to avoid costly limits on discretion to support local lending for members that already supported lending in the past while avoiding moral hazard at the same time. The side-payment technology suggested in this paper works indirectly via the deposit insurance fund. It is available because it uses the same features

\footnotetext{
${ }^{10}$ Section 4 relaxes this assumption and extends the model to an infinite horizon. The main insight is that discretion of a local regulator that becomes more "indebted" to the deposit insurance fund tends to decrease slowly while discretion of a regulator that becomes more of a "creditor" tends to increase quickly. The latter is allowed to engage in state-contingent excessive leniency to make such an emphasis on rewards over punishments incentive-compatible. The role of Assumption 2 is to avoid this channel "going missing" in the two-period benchmark version of the model where $P$ has a kink at $v=v_{0}$.
} 
of the banking union that are also involved in creating the moral hazard motive in the first place. ${ }^{11}$

Insufficient regulatory discretion may be one reason why some countries in the European Union have suffered a more severe financial crisis compared with the 2007-2009 US financial crisis. ${ }^{12}$ However, Proposition 1 suggests that members of a banking union should have discretion to address local lending demand even if they already accommodated such demand in the past. Members not in need of supporting local lending themselves can help to maintain incentives by nevertheless supporting their own local lending to some degree. In that sense, members that are creditors to the deposit insurance fund should "stimulate" their local economy with increased bank lending rather than requiring limited discretion, or "austerity," by members that are indebted to the deposit insurance fund.

When members of a banking union coordinate lending optimally, past economic conditions affect future expected withdrawals from the deposit insurance fund. This holds even though economic conditions are assumed to be independent across members and over time. Specifically, Corollary 2 gives sufficient conditions for when past disagreement regarding the need for leniency across local regulators leads to higher expected leniency and thus to higher expected losses to the deposit insurance fund. In that sense, financial stability declines when regulators had different shocks-i.e., different needs to exercise leniency-in the past.

Figure 2 illustrates that discretion is a convex function of promised second-period

\footnotetext{
${ }^{11}$ Dell'Ariccia and Marquez (2006) analyze the trade-off between a loss of discretion and a reduction of moral hazard when central supervision imposes the same policy on each member of a banking union (as in section 3.1 of this paper). They find that with loss of discretion, central supervision improves welfare only if members are sufficiently similar. Their argument is related to the criteria for currency areas developed in Mundell (1961).

${ }^{12}$ Another potential difference is that the United States may have higher fiscal capacity to support lending during a financial crisis. For example, the Troubled Asset Relief Program (TARP) and the Temporary Liquidity Guarantee Program (TLGP) may have benefited from the possibility of obtaining funding from the US Treasury. I discuss distortionary local taxation as a direct side-payment technology in section 3.5.
} 


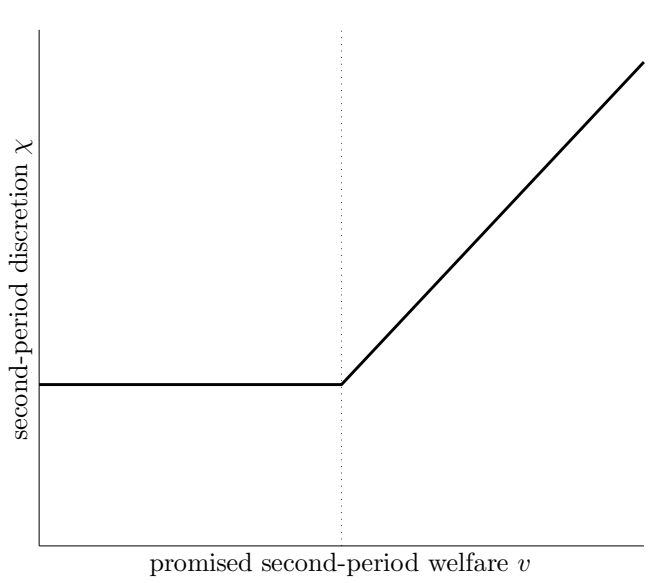

(a) Discretion $\chi_{j, 2}$

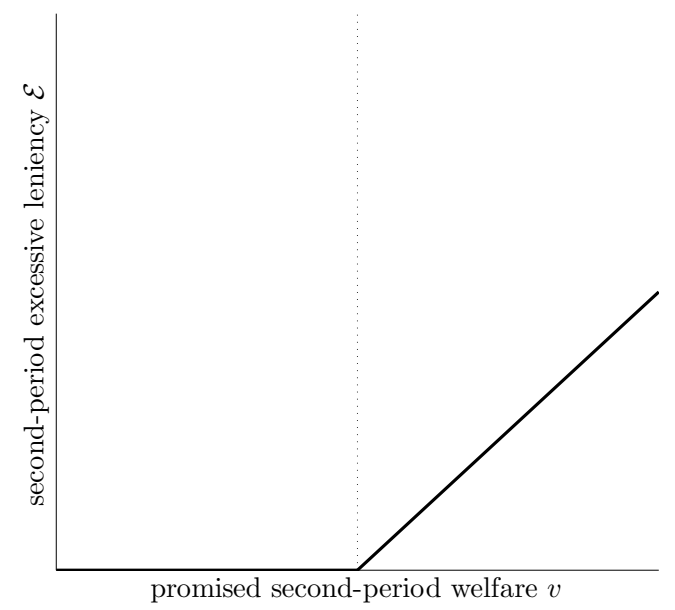

(b) Excessive leniency $\mathcal{E}_{j, 2}$

Figure 2: Panel 2a illustrates that a local regulator's discretion to exercise leniency $\chi_{j, 2}$-as measured by $\ell_{1}\left(\theta_{H}, \theta_{L}\right)$ and $\ell_{2}\left(\theta_{L}, \theta_{H}\right)$, respectively-is a convex function of its second-period welfare in the case where $\theta_{H} \leq 2 \theta_{L}$ (Corollary 2). Panel $2 \mathrm{~b}$ illustrates that only local regulators with relatively higher second-period welfare engage in excessive leniency $\mathcal{E}_{j, 2}$ as measured by $\ell_{1}\left(\theta_{L}, \theta_{H}\right)$ and $\ell_{2}\left(\theta_{H}, \theta_{L}\right)$, respectively. The dotted lines indicate symmetric second-period welfare of $v_{0}$.

welfare when shocks are not too far apart, $\theta_{H} \leq 2 \theta_{L}$, such that local regulators are rewarded with higher discretion but never punished with lower discretion. As a result, expected leniency is higher whenever local regulators experienced different shocks in the past when $\theta_{H} \leq 2 \theta_{L}$.

Corollary 2. Suppose $3 \sigma-\mu \leq 0$, or equivalently $\theta_{H} \leq 2 \theta_{L}$. Let $\theta_{1}, \theta_{2}$ be shocks in the first period. If $\theta_{i}<\theta_{j}$-i.e., local regulator $j$ was relatively more lenient in the first period-then in period two, compared with the case where $\theta_{1}=\theta_{2}$,

1. expected leniency across local regulators is strictly higher,

2. discretion of local regulator $j$ is not reduced; in fact, leniency of local regulator $j$ is the same.

Proof. The result follows from Lemmas 3 and 4 together with Lemma 5. 


\subsection{Indirect and direct side-payment technologies}

It was shown in section 3.3 that optimal supervision makes use of an indirect sidepayment technology in the second period if (and only if) local regulators had different shocks in the first period. Suppose regulator two had a relatively higher shock in the first period. Then second-period excessive leniency of regulator one, $\ell_{1}\left(\theta_{L}, \theta_{H}\right)>0$, implies a costly side payment from regulator two to regulator one. To see this, note that regulator two experiences a net loss of $\frac{1}{2} \ell_{1}\left(\theta_{L}, \theta_{H}\right)$ while regulator one enjoys a net benefit of $\left(\theta_{L}-1 / 2\right) \ell_{1}\left(\theta_{L}, \theta_{H}\right)$. This implicit payment is costly, since the economy-wide net benefit $\theta_{L}-1$ is negative, but it allows regulator two to pay for having higher leniency repeatedly; i.e.; in the second period $\ell_{1}\left(\theta_{L}, \theta_{H}\right)>0$ reduces the need to reduce $\ell_{2}\left(\theta_{L}, \theta_{H}\right)$. In the case where $\theta_{H} \leq 2 \theta_{L}$ (Corollary 2), the indirect side-payment technology is attractive enough to make second-period leniency of regulator two independent of the shock it reported in the first period.

Suppose there is also a direct side-payment technology in the form of a local fiscal backstop that allows local regulators to contribute individually to the deposit insurance fund, or equivalently, to directly pay for the losses associated with local leniency. It is assumed that local fiscal backstops are distorting in the sense that regulator two must incur a loss of 1 when regulator one is to enjoy a benefit of $\lambda<1$. The parameter $\lambda$ captures the fiscal capacity of each member of the banking union such that a higher fiscal capacity lowers the cost of the direct side-payment technology.

Lemma 6. The direct side-payment technology is equivalent to the indirect side-payment technology when fiscal capacity is $\lambda=2 \theta_{L}-1 \in(0,1)$, it dominates when $\lambda>2 \theta_{L}-1$, and it is not used otherwise.

Proof. Follows immediately from the preceding discussion.

When financial sector industry levies are used to pay for defaults associated with le- 
niency, then economic distortions may be smaller compared with the case in which local fiscal backstops are used (ASC, 2012), which is captured by $\lambda<1$. However, reliance on a deposit insurance or resolution fund backed by uniform industry levies leads to incentive distortions as it creates negative externalities from local leniency. Lemma 6 shows that, unless fiscal capacity exceeds $2 \theta_{L}-1$, there is no reason to augment the banking union's fund with local fiscal backstops. Supervision has access to an indirect side-payments technology that supports maintaining high discretion over time even if fiscal backstops are not available due to limited fiscal capacity.

\subsection{Relation to literature on risk sharing and optimal delegation}

The tightening of coordination over time, in the sense of state-contingent excessive leniency, following past disagreement is the result of the interaction of two channels for incentive provision that have been studied extensively, albeit separately, in the literature. This paper, on the other hand, focuses on the interaction of intratemporal margins (e.g., Roberts, 1985) and intertemporal margins (e.g., Taub, 1994) for incentive provision. For instance, many dynamic contracting problems have a solution that features (ex-post) inefficiently high consumption of sufficiently wealthy lenders as a reward for past frugality (e.g., Thomas and Worrall, 1990; Atkeson and Lucas, 1992; Iovino and Golosov, 2013). However, in this paper, such excessive leniency is employed only in certain states, and after certain histories, as a means of providing additional incentives via immediate reciprocity. As a result, "debtors" may not be required to repay (Corollary 2). These features of my model are new relative to the existing risk-sharing literature and generate novel policy implications.

In Amador and Bagwell $(2012,2013)$, agents cause negative externalities, such as import tariffs, on each other but contract separately with a principal who wishes to 
limit excessive externalities. I allow for this simultaneity to matter for contracting such that an indirect side-payment technology is being created, which becomes useful after certain histories. For example, a country facing a trading partner that imposes relatively higher import restrictions, after having already done so in the past, should respond immediately by imposing high import restrictions as well, even if this leads to lower joint welfare ex-post. That is, retaliatory tariffs can become temporarily optimal over time. My model also suggests that regional trade agreements are more effective at lowering trade barriers than agreements at the level of the World Trade Organization (Baldwin, 2016) (since retaliatory tariffs can be better targeted when there are fewer participants).

\section{Extension to Infinite Horizon}

Consider now the case of infinitely many time periods, $t=0,1,2, \ldots$ Suppose each local regulator enjoys instantaneous utility payoffs from local leniency $\ell \in X \subset \mathbb{R}_{+}$ given by the function $u: \mathbb{R}_{+} \times \Theta \rightarrow \mathbb{R}$. On the set $\Theta=\left\{\theta_{1}, \theta_{2}, \ldots, \theta_{N}\right\}$, an independent and identically distributed (i.i.d.), across local regulators and over time, uniformly distributed discrete random variable $\theta$ is defined. Its realizations are ordered, $0<\theta_{1}<\cdots<\theta_{N}<\infty$. Future payoffs are discounted by $\delta \in(0,1)$. It is assumed that $u(\ell, \theta)$ is twice continuously differentiable and strictly concave in $\ell$, strictly increasing in $\theta$, and that $u^{\prime}(\ell, \theta)=\frac{\partial u(\ell, \theta)}{\partial \ell}$ is strictly increasing in $\theta$. Payoffs are single-peaked in the sense that, for some $l<\infty, \frac{\partial u\left(\ell, \theta_{N}\right)}{\partial \ell} \geq 0$ for $\ell \leq l$ and $\frac{\partial u\left(\ell, \theta_{N}\right)}{\partial \ell}<0$ for $\ell>l$. Without loss of generality, we can therefore restrict attention to levels of leniency taking values on the interval $X=[0, L]$ for some $L>l$. Specifically, assume that $u(\ell, \theta)=\theta v(\ell)-\frac{1}{2} \ell$, where $v$ is strictly increasing, strictly concave and twice differentiable. ${ }^{13}$ Due to joint

\footnotetext{
${ }^{13}$ In section $2, v(\ell)=\min (\ell, 1)$ and the effective upper bound on leniency 1 was arbitrary.
} 
contributions to the deposit insurance fund, the net payoff of local regulator $i$ is given by $u\left(\ell_{i}, \theta^{i}\right)-\frac{1}{2} \ell_{j}$ where $j$ denotes local regulator $j \neq i$ and $\theta^{i}$ is the parameter of local regulator $i$. The joint net payoff to local regulators is given by

$$
u\left(\ell_{1}, \theta^{1}\right)+u\left(\ell_{2}, \theta^{2}\right)-\frac{1}{2} \ell_{1}-\frac{1}{2} \ell_{2}
$$

when $\ell_{1}, \ell_{2}$ are the respective actions by the two local regulators.

Definition 1. First-best leniency is defined by the function $\ell^{F B}: \Theta \rightarrow X$ such that $u^{\prime}\left(\ell^{F B}(\theta), \theta\right)=$ $\frac{1}{2}$, for all $\theta \in \Theta$. Privately optimal leniency is defined by the function $\ell^{*}: \Theta \rightarrow X$ such that $u^{\prime}\left(\ell^{*}(\theta), \theta\right)=0$, for all $\theta \in \Theta$. Note that $\ell^{F B}<\ell^{*}$ uniformly on $\Theta$.

Note that a local regulator's net payoff is highest when its leniency is $\ell^{*}$, for given leniency of the respective other local regulator. Also note that the sum of net payoffs across regulators is highest when leniency is given by $\ell^{F B}$ for each local regulator.

\subsection{Recursive formulation}

Optimal supervision of local regulators is characterized by solving for the Pareto set of discounted expected values of net payoffs to each local regulator. As is standard in the literature, values in the Pareto set are delivered by a combination of current leniency and future (continuation) values. For a given current value of local regulator two, $v \in V$, define the functions for leniency $\ell_{i}: \Theta^{2} \rightarrow X$ and continuation values $v_{i}: \Theta^{2} \rightarrow V$, $i=1,2$. Let $V=[\underline{v}, \bar{v}]$, where the lower bound on $V$ is motivated by Assumption 3, which is an analogue to Assumption 1, and the upper bound is defined below.

Assumption 3. At the beginning of each period, before observing its parameter, either local regulator has the option to demand that the supervisor prescribe optimal static no-coordination policies for both local regulators from the current period onward. The optimal static no-coordination 
policy is an optimally chosen upper bound $\bar{\ell}$ on leniency and yields the value of

$$
\underline{v}=\max _{\bar{\ell}} \frac{1}{1-\delta} \frac{1}{N} \sum_{i=1}^{N}\left[u\left(\tilde{\ell}\left(\theta_{i}\right), \theta_{i}\right)-\frac{1}{2} \tilde{\ell}\left(\theta_{i}\right)\right] \text { where } \tilde{\ell}\left(\theta_{i}\right)=\min \left(\bar{\ell}, \ell^{*}\left(\theta_{i}\right)\right) \forall \theta_{i} \in \Theta \text {. }
$$

That is, any policy that a supervisor prescribes must yield values of at least $\underline{v}$ for either local regulator.

Define an operator $T$ on $C(V)$, the space of continuous, decreasing, and concave functions on $V$, by

$$
\begin{aligned}
(T f)(v) & =\max _{\ell_{1}, \ell_{2}, v_{1}, v_{2}} \frac{1}{N^{2}} \sum_{\left(\theta_{i}, \theta_{j}\right) \in \Theta^{2}}\left[u\left(\ell_{1}\left(\theta_{i}, \theta_{j}\right), \theta_{i}\right)-\frac{1}{2} \ell_{2}\left(\theta_{i}, \theta_{j}\right)+\delta v_{1}\left(\theta_{i}, \theta_{j}\right)\right] \\
& \text { subject to } \\
& \frac{1}{N^{2}} \sum_{\left(\theta_{i}, \theta_{j}\right) \in \Theta^{2}}\left[u\left(\ell_{2}\left(\theta_{i}, \theta_{j}\right), \theta_{j}\right)-\frac{1}{2} \ell_{1}\left(\theta_{i}, \theta_{j}\right)+\delta v_{2}\left(\theta_{i}, \theta_{j}\right)\right] \geq v \\
& \frac{1}{N} \sum_{\theta_{j} \in \Theta}\left[u\left(\ell_{1}\left(\theta_{i}, \theta_{j}\right), \theta_{i}\right)-\frac{1}{2} \ell_{2}\left(\theta_{i}, \theta_{j}\right)+\delta v_{1}\left(\theta_{i}, \theta_{j}\right)\right] \\
& \geq \frac{1}{N} \sum_{\theta_{j} \in \Theta}\left[u\left(\ell_{1}\left(\theta_{i+1}, \theta_{j}\right), \theta_{i}\right)-\frac{1}{2} \ell_{2}\left(\theta_{i+1}, \theta_{j}\right)+\delta v_{1}\left(\theta_{i+1}, \theta_{j}\right)\right], \quad i=1,2, \ldots, N-1 \\
& \frac{1}{N} \sum_{\theta_{i} \in \Theta}\left[u\left(\ell_{2}\left(\theta_{i}, \theta_{j}\right), \theta_{j}\right)-\frac{1}{2} \ell_{1}\left(\theta_{i}, \theta_{j}\right)+\delta v_{2}\left(\theta_{i}, \theta_{j}\right)\right] \\
& \geq \frac{1}{N} \sum_{\theta_{i} \in \Theta}\left[u\left(\ell_{2}\left(\theta_{i}, \theta_{j+1}\right), \theta_{j}\right)-\frac{1}{2} \ell_{1}\left(\theta_{i}, \theta_{j+1}\right)+\delta v_{2}\left(\theta_{i}, \theta_{j+1}\right)\right], \quad j=1,2, \ldots, N-1 \\
& v_{1}\left(\theta_{i}, \theta_{j}\right) \leq f\left(v_{2}\left(\theta_{i}, \theta_{j}\right)\right), \quad v_{2}\left(\theta_{i}, \theta_{j}\right) \in V, \text { for all } i, j=1,2, \ldots, N .
\end{aligned}
$$

The maximization problem yields the highest possible value for local regulator one given that local regulator two receives value of at least $v$ where "feasibility" of the (continuation) values $v_{1}, v_{2}$ is determined by the function $f .{ }^{14}$ The upper bound on

\footnotetext{
${ }^{14}$ Lemma 9 in Appendix A.1 shows that, as long as leniency of each local regulator is increasing in its shock, it is sufficient to focus on adjacent upward incentive constraints.
} 
feasible values is then given by $\bar{v}=P(\underline{v})$.

Lemma 7. Thas a unique fixed point $P$ that is strictly decreasing, strictly concave, and continuously differentiable on $V$. The Pareto set $\left\{\left(v_{1}, v_{2}\right): v_{1}=P\left(v_{2}\right), v_{2} \in V\right\}$ is self-generating (see Abreu et al., 1990) in the sense that constraint (20) is always binding for $f=P$.

Proof. See Appendix A.1.

Definition 2. The set of feasible (continuation) values is defined by $\left\{\left(v_{1}, v_{2}\right): v_{1} \leq P\left(v_{2}\right), v_{2} \in\right.$ $V\}$.

Definition 3. Denote the symmetric (promised) value by $\hat{v}=P(\hat{v})$.

The properties of $P$ that Lemma 7 establishes are helpful since optimal leniency and continuation values can be characterized by examining first-order conditions from problem (16) where $f=P$. The optimality conditions for leniency $\ell_{1}$ and $\ell_{2}$, respectively, are

$$
\begin{gathered}
u^{\prime}\left(\ell_{1}\left(\theta_{i}, \theta_{j}\right), \theta_{i}\right)\left[1+\psi_{1}\left(\theta_{i}\right)\right]-u^{\prime}\left(\ell_{1}\left(\theta_{i}, \theta_{j}\right), \theta_{i-1}\right) \psi_{1}\left(\theta_{i-1}\right)=\frac{1}{2}\left[\tau+\psi_{2}\left(\theta_{j}\right)-\psi_{2}\left(\theta_{j-1}\right)\right], \\
u^{\prime}\left(\ell_{2}\left(\theta_{i}, \theta_{j}\right), \theta_{j}\right)\left[\tau+\psi_{2}\left(\theta_{j}\right)\right]-u^{\prime}\left(\ell_{2}\left(\theta_{i}, \theta_{j}\right), \theta_{j-1}\right) \psi_{2}\left(\theta_{j-1}\right)=\frac{1}{2}\left[1+\psi_{1}\left(\theta_{i}\right)-\psi_{1}\left(\theta_{i-1}\right)\right]
\end{gathered}
$$

where $\tau, \psi_{1}$, and $\psi_{2}$ are the Lagrange multipliers on constraints (17), (18), and (19), respectively. The optimality conditions for continuation payoffs $v_{2}$ and envelope conditions are given by

$$
\begin{aligned}
-P^{\prime}\left(v_{2}\left(\theta_{i}, \theta_{j}\right)\right) & =\frac{\tau+\psi_{2}\left(\theta_{j}\right)-\psi_{2}\left(\theta_{j-1}\right)}{1+\psi_{1}\left(\theta_{i}\right)-\psi_{1}\left(\theta_{i-1}\right)} \\
-P^{\prime}(v) & =\tau .
\end{aligned}
$$


Lemma 8 summarizes some straightforward implications of these conditions.

Lemma 8. Conditions (21) to (24) have the following implications:

1. The geometric mean of realized marginal net payoffs is always bounded above by $\frac{1}{2}$, the first-best marginal utility,

$$
\sqrt{u^{\prime}\left(\ell_{1}\left(\theta_{i}, \theta_{j}\right), \theta_{i}\right) u^{\prime}\left(\ell_{2}\left(\theta_{i}, \theta_{j}\right), \theta_{j}\right)} \leq \frac{1}{2}
$$

for $i, j=1,2, \ldots, N$ with equality only if $i=j=1$.

2. If $v=\hat{v}$, then $v_{2}\left(\theta_{i}, \theta_{i}\right)=v=\hat{v}$ for $i=1,2, \ldots, N$.

3. $\ell_{1}\left(\theta_{i}, \theta_{j}\right) \leq \ell_{1}\left(\theta_{i}, \theta_{j+1}\right)$ if and only if $v_{2}\left(\theta_{i}, \theta_{j}\right) \geq v_{2}\left(\theta_{i}, \theta_{j+1}\right)$, for $i=1,2, \ldots, N$ and $j=1,2, \ldots, N-1$.

4. $\ell_{2}\left(\theta_{i}, \theta_{j}\right) \leq \ell_{2}\left(\theta_{i+1}, \theta_{j}\right)$ if and only if $v_{1}\left(\theta_{i}, \theta_{j}\right) \geq v_{1}\left(\theta_{i+1}, \theta_{j}\right)$, for $j=1,2, \ldots, N$ and $i=1,2, \ldots, N-1$.

5. $v_{1}\left(\theta_{i}, \theta_{j}\right)>\hat{v}$ implies $u^{\prime}\left(\ell_{1}\left(\theta_{i}, \theta_{j}\right), \theta_{i}\right) \leq \frac{1}{2}$, and $v_{2}\left(\theta_{i}, \theta_{j}\right)>\hat{v}$ implies $u^{\prime}\left(\ell_{2}\left(\theta_{i}, \theta_{i}\right), \theta_{j}\right) \leq$ $\frac{1}{2}$, for $i, j=1,2, \ldots, N$.

Proof. See Appendix A.1.

Lemma 9 in Appendix A.1 shows that, as long as leniency of each local regulator is increasing in its shock-as in the numerical example considered below-it is sufficient to focus on adjacent upward incentive constraints in order to ensure incentive compatibility of the allocation. In that case, Lemma 8 characterizes features of optimal supervision of local regulators.

When leniency of each local regulator is increasing in its shock, then Lemma 8 gives a sense of the way in which, on average, local regulator leniency is higher than first-best. 
It also shows that if both local regulators enjoy the same value along the Pareto frontier, then they will continue to do so as long as they receive the same shock, independent of the level of that shock. It is further shown that if optimal supervision uses continuation values to incentivize a local regulator, then it also uses leniency of the respective other local regulator to incentivize the former, and vice versa. Finally, Lemma 8 shows that a regulator that is awarded a higher continuation value in a particular state is also allowed to engage in excessive leniency in that state. Such a local regulator has a relatively higher current value; i.e., has received relatively lower shocks in the past, or is experiencing a relatively lower shock in the current period, or both. When both is the case, then Lemma 8 suggests an infinite-horizon analogue to Proposition 1. That is, the local regulator that exercised relatively less leniency in the past is allowed to engage in statecontingent excessive leniency in the current period.

\subsubsection{Numerical exercise}

In the two-period version of the model, one can solve for optimal supervision by hand and characterize analytically an emphasis on rewards over punishment. Recall that Corollary 2 gives conditions under which discretion is a convex function of second-period welfare in the two-period version of the model, as shown in Figure 2. This section presents a numerical example with $v(\ell)=2 \sqrt{\ell}, \delta=0.8, N=5$, and $\Theta=\{0.5,0.625,0.75,0.875,1\}$. Figure 4 shows that discretion $\chi$ is convex in promised value around the symmetric value $\hat{v}$, and that excessive leniency $\mathcal{E}$ increases in promised value. ${ }^{15}$ The insights from section 3 are confirmed: local regulators get rewarded

\footnotetext{
${ }^{15}$ The definitions for discretion and excessive leniency are as follows:

$$
\begin{aligned}
& \chi=\frac{1}{N} \sum_{i=1}^{N}\left[\ell_{2}\left(\theta_{i}, \theta_{N}\right)-\min \left(\ell_{2}\left(\theta_{i}, \theta_{1}\right), \ell^{F B}\left(\theta_{1}\right)\right)\right], \\
& \mathcal{E}=\frac{1}{N} \sum_{j=1}^{N}\left[\ell_{2}\left(\theta_{N}, \theta_{j}\right)-\ell_{2}\left(\theta_{1}, \theta_{j}\right)\right] \cdot \mathbb{1}_{\ell_{2}\left(\theta_{N}, \theta_{j}\right) \geq \ell^{F B}\left(\theta_{N}\right)},
\end{aligned}
$$
}




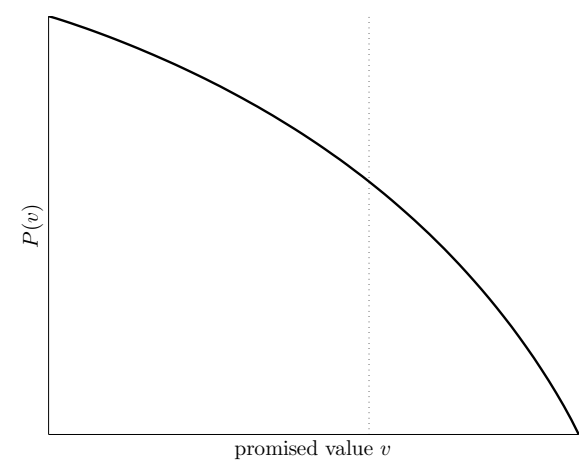

(a) Pareto frontier $P$

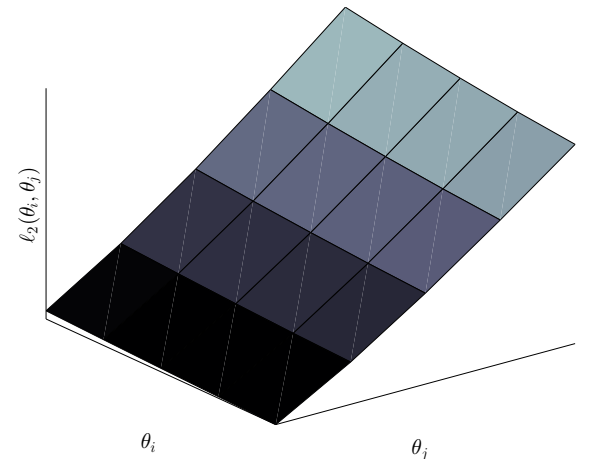

(b) Leniency of local regulator two $\ell_{2}$

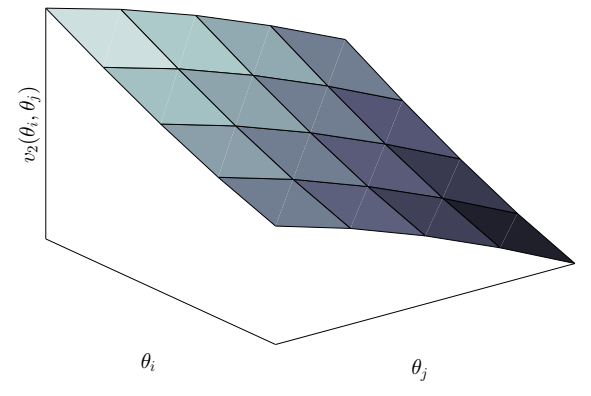

(c) Continuation value of local regulator two $v_{2}$

Figure 3: The dotted line in panel 3a indicates the symmetric value $\hat{v}$ in the numerical example. Panels $3 b$ and $3 c$ show $\ell_{2}$ and $v_{2}$, respectively, when the value promised to local regulator two is $\hat{v}$.

with increased discretion rather than punished with reduced discretion, which is made incentive-compatible by allowing the local regulator that was relatively less lenient in the past to engage in state-contingent excessive leniency. Figure 4c shows, in an analogue to Corollary 2, that expected leniency across local regulators is higher the more regulatory stances differed in the past, i.e. the further current promised values are apart.

where $\mathbb{1}$ is the indicator function. Note that $\ell^{F B}(\theta)=\theta^{2}$ when $v(\ell)=2 \sqrt{\ell}$. The role of the min-operator in the definition of $\chi$ is to avoid a higher measure of excessive leniency reducing measured discretion. The role of the indicator function in the definition of $\mathcal{E}$ is to focus on immediate reciprocity that involves excessive leniency. 


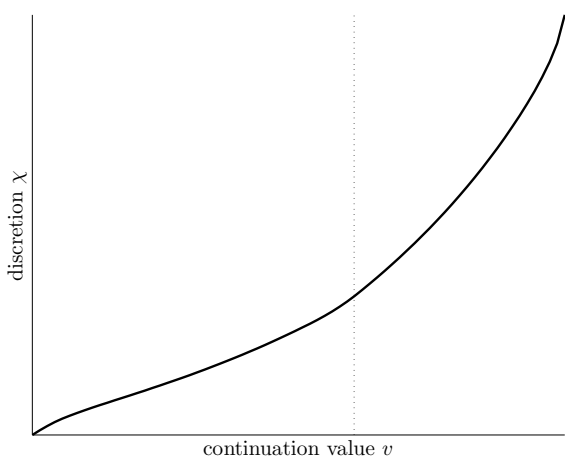

(a) Discretion $\chi$

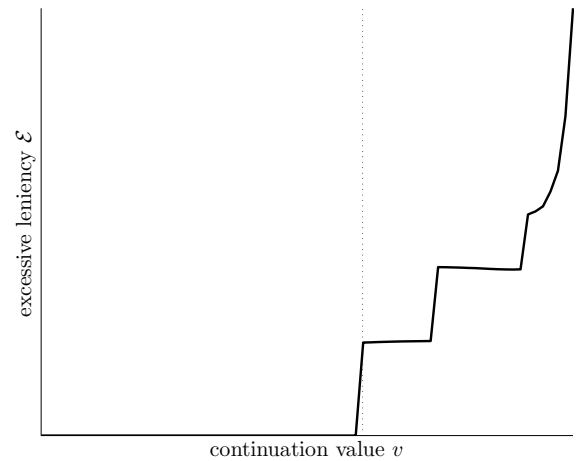

(b) Excessive leniency $\mathcal{E}$

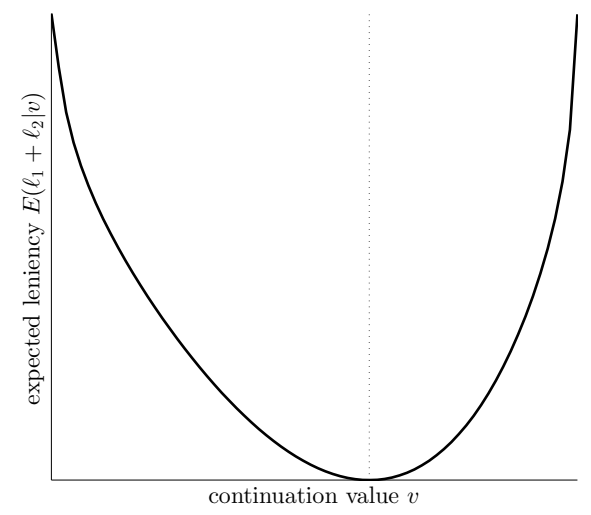

(c) Expected leniency $E\left(\ell_{1}+\ell_{2} \mid v\right)$

Figure 4: Panel 4a and 4b confirm the intuition gained from Figure 2 in the context of the numerical example. Local regulators get rewarded with increased discretion to a relatively higher degree than they are punished with reduced discretion. Incentive compatibility is maintained by allowing the local regulator that was relatively less lenient in the past to engage in statecontingent excessive leniency. Figure $4 \mathrm{c}$ shows that, as a result, expected leniency across local regulators is higher the further apart promised values are. The dotted line indicates the symmetric value $\hat{v}$. 


\section{Conclusion}

Financial regulators sometimes oversee lending booms that have the potential to create bank losses from non-performing loans far exceeding the deposit insurance fund balance. In addition, financial regulators sometimes help maintain lending by banks with high levels of non-performing loans by providing further guarantees via the deposit insurance fund. In both cases, banks that lend to higher-quality borrowers may be asked to increase their contributions to the deposit insurance fund. When banks are competitive, such policies may create negative spillovers among borrowers of different types. Unless members of a banking union implement identical lending policies for each type of borrower, spillovers among members, and with it concerns about moral hazard, can arise.

In this paper, I show that a supervisor of local financial regulators in a banking union can do better than imposing uniform policies at all times. Under optimal supervision, local regulators enjoy some discretion with respect to their policy stance. In order to strengthen incentives for local regulators to share relevant information, they should be supervised jointly, rather than separately: optimal supervision coordinates regulatory leniency across local regulators within each period.

The first major insight is that optimal supervision focuses more on rewarding past restraint than on punishing past leniency. Specifically, a local regulator that exercised relatively more leniency in the past may therefore not be required to reduce its discretion to exercise leniency in the future. The second major insight is that past disagreement about regulatory policy stances across local regulators causes financial stability to deteriorate in the future. Specifically, when local regulators exercised different degrees of leniency in the past, then expected leniency in the future may increase, imposing higher expected losses on an economy-wide deposit insurance fund. 


\section{References}

Abreu, D., D. Pearce, and E. Stacchetti (1990). Toward a theory of discounted repeated games with imperfect monitoring. Econometrica: Journal of the Econometric Society, 1041-1063.

Agarwal, S., D. Lucca, A. Seru, and F. Trebbi (2014). Inconsistent regulators: Evidence from banking. Quarterly Journal of Economics 129(2).

Agur, I. (2013). Multiple bank regulators and risk taking. Journal of Financial Stability 9(3), 259-268.

Amador, M. and K. Bagwell (2012). Tariff revenue and tariff caps. The American Economic Review 102(3), 459-465.

Amador, M. and K. Bagwell (2013). The theory of optimal delegation with an application to tariff caps. Econometrica 81(4), 1541-1599.

Amador, M., I. Werning, and G. Angeletos (2006). Commitment vs. flexibility. Econometrica 74(2), 365-396.

ASC (2012). Forbearance, resolution and deposit insurance. Reports of the Advisory Scientific Committee of the European Systemic Risk Board.

Atkeson, A. and R. E. Lucas (1992). On efficient distribution with private information. The Review of Economic Studies 59(3), 427-453.

Baldwin, R. (2016). The world trade organization and the future of multilateralism. The Journal of Economic Perspectives 30(1), 95-115.

Basel Committee on Banking Supervision (2010). Basel III: A global regulatory framework for more resilient banks and banking systems. 
Carletti, E., G. Dell'Ariccia, and R. Marquez (2015). Supervisory incentives in a banking union.

Chari, V. and P. Kehoe (2007). On the need for fiscal constraints in a monetary union. Journal of Monetary Economics 54(8), 2399-2408.

Colliard, J.-E. (2014). Monitoring the supervisors: optimal regulatory architecture in a banking union. Available at SSRN 2274164.

Dell'Ariccia, G., D. Igan, and L. U. Laeven (2012). Credit booms and lending standards: Evidence from the subprime mortgage market. Journal of Money, Credit and Banking 44(2-3), 367-384.

Dell'Ariccia, G. and R. Marquez (2006). Competition among regulators and credit market integration. Journal of Financial Economics 79(2), 401-430.

Demirgüç-Kunt, A., E. Kane, and L. Laeven (2015). Deposit insurance around the world: A comprehensive analysis and database. Journal of Financial Stability 20, 155-183.

Foarta, O. D. (2014). Optimal bailouts under partially centralized bank supervision. MIT.

Foarta, O. D. (2015). The limits to partial banking unions: A political economy approach. MIT.

Goltsman, M. and G. Pavlov (2014). Communication in Cournot oligopoly. Journal of Economic Theory 153, 152-176.

Gorton, G. and G. Ordoñez (2016). Good booms, bad booms. Technical report, National Bureau of Economic Research. 
Hellwig, M. F. (2014). Yes Virginia, there is a European banking union! But it may not make your wishes come true. MPI Collective Goods Preprint (2014/12).

Holthausen, C. and T. Rønde (2004). Cooperation in international banking supervision.

Huizinga, H. and L. Laeven (2012). Bank valuation and accounting discretion during a financial crisis. Journal of Financial Economics 106(3), 614-634.

Iovino, L. and M. Golosov (2013). Social insurance, information revelation, and lack of commitment. In 2013 Meeting Papers, Number 1020. Society for Economic Dynamics.

Kocherlakota, N. R. (1996). Implications of efficient risk sharing without commitment. The Review of Economic Studies 63(4), 595-609.

Melumad, N. and T. Shibano (1991). Communication in settings with no transfers. The RAND Journal of Economics, 173-198.

Milgrom, P. and I. Segal (2002). Envelope theorems for arbitrary choice sets. Econometrica $70(2), 583-601$.

Mundell, R. A. (1961). A theory of optimum currency areas. The American Economic Review 51(4), 657-665.

Reinhart, C. M. and K. Rogoff (2009). This time is different. Eight Centuries of Financial Folly, Princeton University, Princeton and Oxford.

Roberts, K. (1985). Cartel behaviour and adverse selection. The Journal of Industrial Economics 33(4), 401-413.

Sanguinetti, P. and M. Tommasi (2004). Intergovernmental transfers and fiscal behavior insurance versus aggregate discipline. Journal of International Economics 62(1), 149-170.

Santoro, S. (2015). Fiscal moral hazard in a monetary union. 
Schularick, M. and A. M. Taylor (2012). Credit booms gone bust: Monetary policy, leverage cycles, and financial crises, 1870-2008. The American Economic Review 102(2), 1029.

Stokey, N. L. and R. Lucas (1989). Recursive methods in economic dynamics. Harvard University Press.

Tanner, N. (2013). Optimal delegation under uncertain bias.

Taub, B. (1994). Currency and credit are equivalent mechanisms. International Economic Review, 921-956.

Thomas, J. and T. Worrall (1990). Income fluctuation and asymmetric information: An example of a repeated principal-agent problem. Journal of Economic Theory 51(2), 367390.

Zoican, M. A. and L. Gornicka (2015). Banking union optimal design under moral hazard.

\section{A Appendix}

\section{A.1 Proofs}

Proof of Lemma 1. This is immediate from the assumption that $\theta_{L}<1<\theta_{H}$. 
Proof of Lemma 2. Since local regulators have symmetric preferences, and leniency is static, it follows that $\ell_{1}\left(s_{1}, s_{2}\right)=\ell_{2}\left(s_{2}, s_{1}\right)$. The problem can then be written as

$$
\max _{\ell_{1}\left(s_{1}, s_{2}\right) \in[0, l]} 2(1+\delta) \frac{1}{4}\left[\left(\theta_{L}-1\right)\left(\ell_{1}\left(s_{L}, s_{L}\right)+\ell_{1}\left(s_{L}, s_{H}\right)\right)+\left(\theta_{H}-1\right)\left(\ell_{1}\left(s_{H}, s_{L}\right)+\ell_{1}\left(s_{H}, s_{H}\right)\right)\right],
$$

subject to incentive compatibility

$$
\begin{aligned}
& \left(\theta_{L}-\frac{1}{2}\right)\left(\ell_{1}\left(s_{L}, s_{L}\right)+\ell_{1}\left(s_{L}, s_{H}\right)\right)-\frac{1}{2}\left(\ell_{1}\left(s_{L}, s_{L}\right)+\ell_{1}\left(s_{H}, s_{L}\right)\right) \\
& \quad \geq\left(\theta_{L}-\frac{1}{2}\right)\left(\ell_{1}\left(s_{H}, s_{L}\right)+\ell_{1}\left(s_{H}, s_{H}\right)\right)-\frac{1}{2}\left(\ell_{1}\left(s_{L}, s_{H}\right)+\ell_{1}\left(s_{H}, s_{H}\right)\right) .
\end{aligned}
$$

Since this is a linear program, it is sufficient to verify that its first-order conditions are satisfied by the allocation proposed in the lemma. Letting $\psi>0$ denote the multiplier on the incentive compatibility constraint, these conditions are

$$
\begin{aligned}
\ell_{1}\left(s_{L}, s_{L}\right): & \theta_{L}-1+\left(\theta_{L}-\frac{1}{2}\right) \psi-\frac{1}{2} \psi=-\left(1-\theta_{L}\right)(1+\psi)<0, \\
\ell_{1}\left(s_{L}, s_{H}\right): & \theta_{L}-1+\left(\theta_{L}-\frac{1}{2}\right) \psi+\frac{1}{2} \psi<0 \\
\ell_{1}\left(s_{H}, s_{L}\right): & \theta_{H}-1-\left(\theta_{L}-\frac{1}{2}\right) \psi-\frac{1}{2} \psi=0 \\
\ell_{1}\left(s_{H}, s_{H}\right): & \theta_{H}-1-\left(\theta_{L}-\frac{1}{2}\right) \psi+\frac{1}{2} \psi=\theta_{H}-1+\left(1-\theta_{L}\right) \psi>0, \\
& \psi \cdot\left[-\frac{1}{2} \frac{1-\theta_{L}}{\theta_{L}} l-\left(\left(\theta_{L}-\frac{1}{2}\right)\left(\frac{1-\theta_{L}}{\theta_{L}} l+l\right)-\frac{1}{2} l\right)\right]=0 .
\end{aligned}
$$

The first, fourth and fifth conditions clearly hold. To see that the second holds given the third, note that the third condition can be solved for $\psi=\frac{\theta_{H}-1}{\theta_{L}}$ such that

$$
\theta_{L}-1+\left(\theta_{L}-\frac{1}{2}\right) \psi+\frac{1}{2} \psi=\theta_{L}-1+\theta_{L} \psi=\theta_{L}-1+\theta_{H}-1=2(\mu-1)<0,
$$

since $\mu<1$.

Proof of Lemma 3. To make notation simpler, denote $\ell_{i}^{j k}=\ell_{i}\left(s_{j}, s_{k}\right)$ for $j, k \in\{L, H\}$. For use 
throughout this appendix, let us write out first-order conditions for leniency (for given $v$ ).

$$
\begin{array}{lr}
\ell_{1}^{L L}: & \theta_{L}-\frac{1}{2}-\frac{1}{2} \tau+\left(\theta_{L}-\frac{1}{2}\right) \psi_{1}-\frac{1}{2} \psi_{2} \lesseqgtr 0, \\
\ell_{1}^{L H}: & \theta_{L}-\frac{1}{2}-\frac{1}{2} \tau+\left(\theta_{L}-\frac{1}{2}\right) \psi_{1}+\frac{1}{2} \psi_{2} \lesseqgtr 0, \\
\ell_{1}^{H L}: & \theta_{H}-\frac{1}{2}-\frac{1}{2} \tau-\left(\theta_{L}-\frac{1}{2}\right) \psi_{1}-\frac{1}{2} \psi_{2} \lesseqgtr 0, \\
\ell_{1}^{H H}: & \theta_{H}-\frac{1}{2}-\frac{1}{2} \tau-\left(\theta_{L}-\frac{1}{2}\right) \psi_{1}+\frac{1}{2} \psi_{2} \lesseqgtr 0, \\
\ell_{2}^{L L}: & -\frac{1}{2}+\left(\theta_{L}-\frac{1}{2}\right) \tau-\frac{1}{2} \psi_{1}+\left(\theta_{L}-\frac{1}{2}\right) \psi_{2} \lesseqgtr 0, \\
\ell_{2}^{L H}: & -\frac{1}{2}+\left(\theta_{H}-\frac{1}{2}\right) \tau-\frac{1}{2} \psi_{1}-\left(\theta_{L}-\frac{1}{2}\right) \psi_{2} \lesseqgtr 0, \\
\ell_{2}^{H L}: & -\frac{1}{2}+\left(\theta_{L}-\frac{1}{2}\right) \tau+\frac{1}{2} \psi_{1}+\left(\theta_{L}-\frac{1}{2}\right) \psi_{2} \lesseqgtr 0, \\
\ell_{2}^{H H}: & -\frac{1}{2}+\left(\theta_{H}-\frac{1}{2}\right) \tau+\frac{1}{2} \psi_{1}-\left(\theta_{L}-\frac{1}{2}\right) \psi_{2} \lesseqgtr 0,
\end{array}
$$

where $\tau$ is the Lagrange multiplier on the promise-keeping constraint for local regulator two and $\psi_{i}$ is the multiplier on the incentive compatibility constraint for local regulator $i=1,2$. We will compute the optimal allocation for $v \in\left[\underline{v}, v_{0}\right]$, where the case $v \in\left[v_{0}, \bar{v}\right]$ follows from symmetry. $P$ will be piece-wise linear with kinks $\underline{v}_{j}, j=0,1,2$, and $\underline{v}_{2}<\underline{v}_{1}<v_{0}$. Below we will guess and verify optimal leniency that attains $P(v)$ for each $v \in\left[\underline{v}, v_{0}\right]$.

For $v \in\left[\underline{v}_{1}, v_{0}\right]$, we have that $\ell_{1}^{L H}, \ell_{1}^{H L}, \ell_{2}^{L H}$ take interior values such that (26), (27) and (30) hold with equality. The remaining first-order conditions yield corner solutions $\ell_{1}^{L L}=\ell_{2}^{L L}=$ $\ell_{2}^{H L}=0$ and $\ell_{1}^{H H}=\ell_{2}^{H H}=l$. Both incentive compatibility constraints bind such that multipliers are given by

$$
\tau=2 \mu-1, \quad \psi_{1}=\frac{\sigma^{2}-\mu(1-\mu)}{(\mu-\sigma)(1-\mu+\sigma)}, \quad \psi_{2}=\frac{(2 \mu-1)\left(\sigma^{2}+\mu(1-\mu)\right)}{(\mu-\sigma)(1-\mu+\sigma)} .
$$

Note that $\psi_{1}$ is strictly positive, since discretion matters (according to Assumption 2). To verify that $\ell_{2}^{H L}=0$, note that the left-hand side of (31), whenever the left-hand side of (26) is zero, can 
be written as $\theta_{L}(\tau-1)-\left(1-\theta_{L}\right)\left(\psi_{2}-\psi_{1}\right)<0$.

The interior policies for a given $v \in\left[\underline{v}_{1}, v_{0}\right]$ are

$$
\ell_{1}^{L H}=4\left(v_{0}-v\right), \quad \ell_{1}^{H L}=\frac{1-\mu+\sigma}{\mu-\sigma} l+4\left(v_{0}-v\right), \quad \ell_{2}^{L H}=\frac{1-\mu+\sigma}{\mu-\sigma} l .
$$

We have $\ell_{1}^{H L}=1$ at $v=\underline{v}_{1}$ where

$$
\underline{v}_{1}=\frac{3 \sigma-\mu}{4(\mu-\sigma)} l
$$

Note that $\underline{v}_{1}$ can be either positive or negative. In the former case, we are interested in $v \in\left[0, \underline{v}_{1}\right)$ as well. Then $\ell_{1}^{L H}, \ell_{2}^{L H}$ take interior values such that (26) and (30) hold with equality. The remaining first-order conditions yield corner solutions $\ell_{1}^{L L}=\ell_{2}^{L L}=\ell_{2}^{H L}=0$ and $\ell_{1}^{H L}=$ $\ell_{1}^{H H}=\ell_{2}^{H H}=l$. Only the second local regulator's incentive compatibility constraint binds such that multipliers are given by

$$
\tau=2 \mu-1-\frac{\sigma^{2}-\mu(1-\mu)}{\sigma}, \quad \psi_{1}=0, \quad \psi_{2}=\frac{\sigma^{2}+\mu(1-\mu)}{\sigma},
$$

where it is easy to verify that $\tau \in(0,1)$. We have $\ell_{2}^{H L}=0$ for the same reason as above, since again $\psi_{2}-\psi_{1}>0$. To see that $\ell_{1}^{H L}=l$, note that the left-hand side of (27), whenever the left-hand side of (26) is zero, can be written as $\theta_{H}-\theta_{L}-\psi_{2}=\left(\sigma^{2}-\mu(1-\mu)\right) / \sigma>0$.

The interior policies for a given $v \in\left[\underline{v}_{2}, \underline{v}_{1}\right]$ are

$$
\ell_{1}^{L H}=(2(\mu-\sigma)-1) \frac{4 v+l}{2 \sigma}, \quad \ell_{2}^{L H}=\frac{4 v+(1-2 \sigma) l}{2 \sigma} .
$$

Note that both are decreasing as $v$ decreases; however, $\ell_{1}^{L H}>0$ throughout, such that local regulator one will still engage in state-contingent socially wasteful leniency. We have $\ell_{2}^{\mathrm{LH}}=0$ at $v=\underline{v}_{2}$, but this value does not satisfy Assumption 1, since

$$
\underline{v}_{2}=-\frac{1-2 \sigma}{4} l<0 .
$$


Thus, as $v$ decreases in $\left[0, v_{0}\right]$, we have $\ell_{1}^{H L}$ increasing, $\ell_{1}^{L H}>0$, and $\ell_{2}^{L H}$ non-increasing, whenever discretion matters (in the sense of Assumption 2).

Proof of Lemma 4. When $3 \sigma-\mu \leq 0$, then $\underline{v}_{1}$ in the proof of Lemma 3 is negative. According to Assumption 1, it follows that second-period welfare of any local regulator must be larger than $\underline{v}_{1}$. However, average leniency across local regulators is then uniformly higher when $v \neq v_{0}$ compared with the case where $v=v_{0}$, and strictly higher in states where local regulators receive different preference shocks. It follows that expected leniency is strictly higher when $v \neq v_{0}$ compared with the case where $v=v_{0}$.

Proof of Lemma 5. To see that the constrained optimization problem is convex, note that the objective is linear and that the non-linear constraints can be written as

$$
v_{1}\left(s_{1}, s_{2}\right)-P\left(v_{2}\left(s_{1}, s_{2}\right)\right) \leq 0, \quad\left(s_{1}, s_{2}\right) \in S^{2},
$$

where the left-hand side is convex whenever $P$ is concave in $v_{2}$. To see that $P$ is concave, note that we can use the results from the proof of Lemma 3 to define $P$ as

$$
P(v)= \begin{cases}v_{0}-\tau_{0}\left(v-v_{0}\right) & \text { if } v \in\left[\underline{v}_{1}, v_{0}\right] \\ P\left(\underline{v}_{1}\right)-\tau_{1}\left(v-\underline{v}_{1}\right) & \text { if } v \in\left[\underline{v}_{2}, \underline{v}_{1}\right),\end{cases}
$$

where

$$
\tau_{0}=2 \mu-1, \tau_{1}=2 \mu-1-\frac{\sigma^{2}-\mu(1-\mu)}{\sigma}, \underline{v}_{1}=\frac{3 \sigma-\mu}{4(\mu-\sigma)} l, \text { and, } \underline{v}_{2}=-\frac{1-2 \sigma}{4} l
$$


Due to symmetry in the first period, the first-order conditions for leniency look almost the same as in the proof of Lemma 2:

$$
\begin{array}{ll}
\ell_{1}\left(s_{L}, s_{L}\right): & -\left(1-\theta_{L}\right)(1+\psi)<0, \\
\ell_{1}\left(s_{L}, s_{H}\right): & \theta_{L}-1+\theta_{L} \psi<0, \\
\ell_{1}\left(s_{H}, s_{L}\right): & \theta_{H}-1-\theta_{L} \psi \geq 0, \\
\ell_{1}\left(s_{H}, s_{H}\right): & \theta_{H}-1+\left(1-\theta_{L}\right) \psi>0,
\end{array}
$$

where $\psi=0$ if (13) is slack (or equivalently if (14) is slack). Note that $\psi$ is the Lagrange multiplier on either incentive compatibility constraint. The second line is implied by the third, since $\mu<1$. If the third line would not hold, then $\ell_{1}\left(s_{H}, s_{L}\right)=0$ such that $\psi=0$ (but then $\ell_{1}\left(s_{H}, s_{L}\right)$ should be increased, a contradiction). Hence, we know that $\psi \leq \frac{\theta_{H}-1}{\theta_{L}}$.

Ignoring feasibility, the first-order effect of $v_{j}\left(s_{L}, s_{L}\right)$ is $\frac{\delta}{4}(1+\psi)$, which is positive. But then $v_{1}\left(s_{L}, s_{L}\right)=P\left(v_{2}\left(s_{L}, s_{L}\right)\right)=v_{0}$. Similarly, ignoring feasibility, the first-order effect of $v_{j}\left(s_{H}, s_{H}\right)$ is $\frac{\delta}{4}(1-\psi)$, which is positive, since $\psi<1$. But then $v_{1}\left(s_{H}, s_{H}\right)=P\left(v_{1}\left(s_{H}, s_{H}\right)\right)=v_{0}$ as well. Simplifying notation slightly, we can write (13) as

$$
\ell_{1}^{H L}=\min \left\{l, \frac{1-\theta_{L}}{\theta_{L}} l+\frac{\delta}{\theta_{L}}\left(v_{1}^{L H}-v_{1}^{H L}\right)\right\}
$$

Ignoring feasibility, the first-order effects of $v_{1}^{L H}$ and $v_{1}^{H L}$ are $\frac{\delta}{4}(1+\psi)$ and $\frac{\delta}{4}(1-\psi)$, respectively. Both are positive such that, using symmetry, $v_{1}^{L H}=P\left(v_{2}^{L H}\right)=P\left(v_{1}^{H L}\right)$ and $v_{1}^{H L}=P\left(v_{2}^{H L}\right)=$ $P\left(v_{1}^{L H}\right)$. Hence, we know that second-period welfare pairs are always on the Pareto frontier.

Finally, we need to show that $\Delta_{v} \equiv v_{1}^{L H}-v_{1}^{H L}>0$ at the optimum. At $v_{1}^{H L}=v_{1}^{L H}=v_{0}$, suppose we reduce $v_{1}^{H L}$ by a small $d v>0$; then $\Delta_{v}=\left(-P^{\prime}\left(v_{1}^{H L}\right)+1\right) d v$. The effect on firstperiod welfare per local regulator is

$$
\Delta_{W}=\frac{1}{4}\left[\left(\theta_{H}-1\right) \frac{\delta}{\theta_{L}} \Delta_{v}+\delta\left(-P^{\prime}\left(v_{1}^{H L}\right)-1\right) d v\right]=\frac{\delta}{4 \theta_{L}}\left[-(2 \mu-1) P^{\prime}\left(v_{1}^{H L}\right)-(1-2 \sigma)\right] d v .
$$


For $d v<v_{1}^{H L}-\underline{v}_{1}$, we have $-P^{\prime}\left(v_{1}^{H L}\right)=\tau_{0}=2 \mu-1$ such that $\Delta_{W}=\frac{\delta}{2 \theta_{L}}(\sigma-2 \mu(1-\mu)) d v>$ $\frac{\delta}{2 \theta_{L}} \sigma(1-2 \sigma)$, which is positive, then $\Delta_{v}>0$ at an optimum such that local regulators' secondperiod welfare will be varied to increase discretion in period one $\left(\ell_{1}^{H L}\right.$ is higher than the value in the allocation in Lemma 2).

Proof of Lemma 7. We first show that $T$ maps $C(V)$ into itself. That $T f$ is decreasing follows from the promise-keeping constraint (17). $T f$ is continuous according to Corollary 5 in Milgrom and Segal (2002). To see that $T f$ is concave, take any $v_{0}^{\prime}, v_{0}^{\prime \prime} \in V, \alpha \in(0,1)$. Denote the corresponding policy rules and continuation payoffs by $\ell_{1}^{\prime}, \ell_{2}^{\prime}, v_{1}^{\prime}, v_{2}^{\prime}$ and $\ell_{1}^{\prime \prime}, \ell_{2}^{\prime \prime}, v_{1}^{\prime \prime}, v_{2}^{\prime \prime}$. respectively. While the set of incentive-compatible allocations is generally not convex, we can construct alternative policies and continuation payoffs $\ell_{1}^{a}, \ell_{2}^{a}, v_{1}^{a}, v_{2}^{a}$, which satisfy (17)-(20) for $v_{0}=\alpha v_{0}^{\prime}+(1-\alpha) v_{0}^{\prime \prime}$, as follows:

$$
\begin{aligned}
u\left(\ell_{1}^{a}\left(\theta_{i}, \theta_{j}\right), \theta_{i}\right)-\frac{1}{2} \ell_{2}^{a}\left(\theta_{i}, \theta_{j}\right) & =\alpha\left[u\left(\ell_{1}^{\prime}\left(\theta_{i}, \theta_{j}\right), \theta_{i}\right)-\frac{1}{2} \ell_{2}^{\prime}\left(\theta_{i}, \theta_{j}\right)\right]+(1-\alpha)\left[u\left(\ell_{1}^{\prime \prime}\left(\theta_{i}, \theta_{j}\right), \theta_{i}\right)-\frac{1}{2} \ell_{2}^{\prime \prime}\left(\theta_{i}, \theta_{j}\right)\right], \\
u\left(\ell_{2}^{a}\left(\theta_{i}, \theta_{j}\right), \theta_{j}\right)-\frac{1}{2} \ell_{1}^{a}\left(\theta_{i}, \theta_{j}\right) & =\alpha\left[u\left(\ell_{2}^{\prime}\left(\theta_{i}, \theta_{j}\right), \theta_{j}\right)-\frac{1}{2} \ell_{1}^{\prime}\left(\theta_{i}, \theta_{j}\right)\right]+(1-\alpha)\left[u\left(\ell_{2}^{\prime \prime}\left(\theta_{i}, \theta_{j}\right), \theta_{j}\right)-\frac{1}{2} \ell_{1}^{\prime \prime}\left(\theta_{i}, \theta_{j}\right)\right], \\
\ell_{k}^{a}\left(\theta_{i}, \theta_{j}\right) & >\alpha \ell_{k}^{\prime}\left(\theta_{i}, \theta_{j}\right)+(1-\alpha) \ell_{k}^{\prime \prime}\left(\theta_{i}, \theta_{j}\right), \quad k=1,2, \\
v_{k}^{a}\left(\theta_{i}, \theta_{j}\right) & =\alpha v_{k}^{\prime}\left(\theta_{i}, \theta_{j}\right)+(1-\alpha) v_{k}^{\prime \prime}\left(\theta_{i}, \theta_{j}\right), \quad k=1,2 .
\end{aligned}
$$

The alternative allocation satisfies (17) for $v_{0}=\alpha v_{0}^{\prime}+(1-\alpha) v_{0}^{\prime \prime}$ and, since $f$ is concave, it also satisfies (20). To see that (18), evaluated at the alternative allocation, holds, note that

$$
\begin{aligned}
& \frac{1}{N} \sum_{\theta_{j} \in \Theta}\left[u\left(\ell_{1}^{a}\left(\theta_{i}, \theta_{j}\right), \theta_{i}\right)-u\left(\ell_{1}^{a}\left(\theta_{i+1}, \theta_{j}\right), \theta_{i}\right)-\frac{1}{2}\left(\ell_{2}^{a}\left(\theta_{i}, \theta_{j}\right)-\ell_{2}^{a}\left(\theta_{i+1}, \theta_{j}\right)\right)+\delta\left(v_{1}^{a}\left(\theta_{i}, \theta_{j}\right)-v_{1}^{a}\left(\theta_{i+1}, \theta_{j}\right)\right)\right] \\
& \geq \frac{1}{N} \sum_{\theta_{j} \in \Theta}\left(\theta_{i+1}-\theta_{i}\right)\left[v\left(l_{1}^{a}\left(\theta_{i+1}, \theta_{j}\right)\right)-\alpha v\left(l_{1}^{\prime}\left(\theta_{i+1}, \theta_{j}\right)\right)-(1-\alpha) v\left(l_{1}^{\prime \prime}\left(\theta_{i+1}, \theta_{j}\right)\right)\right]>0
\end{aligned}
$$

where the first inequality follows from the fact that (18) holds for allocations $\ell_{1}^{\prime}, \ell_{2}^{\prime}, v_{1}^{\prime}, v_{2}^{\prime}$ and $\ell_{1}^{\prime \prime}, \ell_{2}^{\prime \prime}, v_{1}^{\prime \prime}, v_{2}^{\prime \prime}$, respectively, and by construction of the alternative allocation, and the second inequality follows by construction of the alternative allocation and the fact that $v$ is increasing and convex. A similar argument shows that (19) is strictly slack evaluated at the alternative alloca- 
tion. However, then $(T f)\left(\alpha v_{0}^{\prime}+(1-\alpha) v_{0}^{\prime \prime}\right) \geq \alpha(T f)\left(v_{0}^{\prime}\right)+(1-\alpha)(T f)\left(v_{0}^{\prime \prime}\right)$ and this inequality can be made strict since (18) and (19) are strictly slack when evaluated at the alternative allocation (the alternative allocation can be strictly improved upon). Hence $T f$ is (strictly) concave and $T: C(V) \rightarrow C(V)$.

To see that $T$ is a contraction, note that $T f \leq T g$ whenever $f \leq g$ and that, since (20) always binds, $T(f+c)=T f+\delta c$ for $c \in \mathbb{R}_{+}$, where $\delta<1$. Suppose (20) does not bind for some $\left(\theta_{i}, \theta_{j}\right)$ such that $v_{1}\left(\theta_{i}, \theta_{j}\right)<f\left(v_{2}\left(\theta_{i}, \theta_{j}\right)\right)$, then the first-order optimality conditions for $v_{1}\left(\theta_{i}, \theta_{j}\right), v_{2}\left(\theta_{i}, \theta_{j}\right)$ and $c_{1}\left(\theta_{i}, \theta_{j}\right)$ yield $\left(u^{\prime}\left(\ell_{1}\left(\theta_{i}, \theta_{j}\right), \theta_{i}\right)-u^{\prime}\left(\ell_{1}\left(\theta_{i}, \theta_{j}\right), \theta_{i-1}\right)\right) \psi_{1}\left(\theta_{i-1}\right)=0$, where $\psi_{1}$ is the Lagrange multiplier on (18). Since there is a unique finite bliss point $\ell_{1}^{*}\left(\theta_{i^{\prime}}\right)$ for each $i^{\prime}=1,2, \ldots, N$ and $\theta_{i}>\theta_{i-1}$, it must be the case that $\psi_{1}\left(\theta_{i-1}\right)=0$, and a similar argument shows that $\psi_{2}\left(\theta_{j-1}\right)=0$. However, $v_{1}\left(\theta_{i}, \theta_{j}\right)$ and $v_{2}\left(\theta_{i}, \theta_{j}\right)$ should then be as high as possible from the first-order conditions for $v_{1}$ and $v_{2}$. Hence, $v_{1}\left(\theta_{i}, \theta_{j}\right)=f\left(v_{2}\left(\theta_{i}, \theta_{j}\right)\right)$ for all $\left(\theta_{i}, \theta_{j}\right)$.

Note that $\left(C(V),\|\cdot\|_{\infty}\right)$, with $\|f\|_{\infty}=\sup _{v \in V}|f(v)|$, is a complete metric space such that $T$ has a unique fixed point $P$. Note that $P$ is strictly concave since $T f$ is strictly concave for any $f \in C(V)$ (see Corollary 1 on page 52 in Stokey and Lucas, 1989). To establish differentiability, note that the set of maximizers (and multipliers) generated by $(T P)\left(v_{0}\right)$ is a singleton for each $v_{0}$ due to strict concavity of $u$ and $P$. The directional derivatives given by corollary 5 in Milgrom and Segal (2002) then coincide. ${ }^{16}$ Hence, $P$ is continuously differentiable on int $V$.

The Pareto set is self-generating since (20) binds strictly for any $f \in C(V)$ ).

Lemma 9. Local regulators report shocks truthfully as long as the inequalities (18) and (19) are satisfied if local regulator leniency is increasing in the local shock.

Proof of Lemma 9. Local regulator one with parameter $\theta_{i}$ cannot benefit from reporting $\theta_{i-1}$ instead if the following expression is positive:

$\frac{1}{N} \sum_{\theta_{j} \in \Theta}\left[u\left(\ell_{1}\left(\theta_{i}, \theta_{j}\right), \theta_{i}\right)-\frac{1}{2} \ell_{2}\left(\theta_{i}, \theta_{j}\right)+\delta v_{1}\left(\theta_{i}, \theta_{j}\right)\right]-\frac{1}{N} \sum_{\theta_{j} \in \Theta}\left[u\left(\ell_{1}\left(\theta_{i-1}, \theta_{j}\right), \theta_{i}\right)-\frac{1}{2} \ell_{2}\left(\theta_{i-1}, \theta_{j}\right)+\delta v_{1}\left(\theta_{i-1}, \theta_{j}\right)\right]$

\footnotetext{
${ }^{16}$ Since there is no enforcement problem in the setup considered the regularity condition of the corollary (non-empty interior of the constraint set at every $v_{0} \in \operatorname{int} V$ ) is always satisfied. See Kocherlakota (1996) for a setup where this is not the case.
} 
Since (18) is satisfied with equality, the expression can be written as

$$
\frac{1}{N} \sum_{\theta_{j} \in \Theta}\left(\theta_{i}-\theta_{i-1}\right)\left(\ell_{1}\left(\theta_{i}, \theta_{j}\right)-\ell_{1}\left(\theta_{i-1}, \theta_{j}\right)\right)
$$

which is positive for $\ell_{1}$ increasing in the shock experienced by regulator one. A similar argument applies to the case of local regulator two.

Iterate on (18) to see that local regulator one with parameter $\theta_{i}$ cannot benefit from reporting $\theta_{i+k}$ instead, with $i+k \leq N$, whenever $\ell_{1}$ is increasing in the shock experienced by regulator one.

Proof of lemma 8. From (21) we have that

$$
\frac{1}{2}\left[\tau+\psi_{2}\left(\theta_{j}\right)-\psi_{2}\left(\theta_{j-1}\right)\right]>u^{\prime}\left(\ell_{1}\left(\theta_{i}, \theta_{j}\right), \theta_{i}\right)\left[1+\psi_{1}\left(\theta_{i}\right)-\psi_{1}\left(\theta_{i-1}\right)\right]
$$

since marginal utilities are strictly increasing in the parameter. Similarly, from (22) we obtain

$$
\frac{1}{2}\left[1+\psi_{1}\left(\theta_{i}\right)-\psi_{1}\left(\theta_{i-1}\right)\right]>u^{\prime}\left(\ell_{2}\left(\theta_{i}, \theta_{j}\right), \theta_{j}\right)\left[\tau+\psi_{2}\left(\theta_{j}\right)-\psi_{2}\left(\theta_{j-1}\right)\right] .
$$

Substituting the second into the first inequality and rearranging yields the first result. The second result follows from conditions (23) and (24) and the fact that local regulators are ex ante identical.

Assume that $\ell_{1}\left(\theta_{i}, \theta_{j}\right) \leq \ell_{1}\left(\theta_{i}, \theta_{j+1}\right)$. Suppose $v_{2}\left(\theta_{i}, \theta_{j}\right)<v_{2}\left(\theta_{i}, \theta_{j+1}\right)$, then $-P^{\prime}\left(v_{2}\left(\theta_{i}, \theta_{j}\right)\right)<$ $-P^{\prime}\left(v_{2}\left(\theta_{i}, \theta_{j+1}\right)\right)$ and therefore $\psi_{2}\left(\theta_{j}\right)-\psi_{2}\left(\theta_{j-1}\right)<\psi_{2}\left(\theta_{j+1}\right)-\psi_{2}\left(\theta_{j}\right)$. It follows that

$$
\begin{gathered}
u^{\prime}\left(\ell_{1}\left(\theta_{i}, \theta_{j}\right), \theta_{i}\right)\left[1+\psi_{1}\left(\theta_{i}\right)\right]-u^{\prime}\left(\ell_{1}\left(\theta_{i}, \theta_{j}\right), \theta_{i-1}\right) \psi_{1}\left(\theta_{i-1}\right) \\
<u^{\prime}\left(\ell_{1}\left(\theta_{i}, \theta_{j+1}\right), \theta_{i}\right)\left[1+\psi_{1}\left(\theta_{i}\right)\right]-u^{\prime}\left(\ell_{1}\left(\theta_{i}, \theta_{j+1}\right), \theta_{i-1}\right) \psi_{1}\left(\theta_{i-1}\right) \\
\Leftrightarrow\left[u^{\prime}\left(\ell_{1}\left(\theta_{i}, \theta_{j}\right), \theta_{i}\right)-u^{\prime}\left(\ell_{1}\left(\theta_{i}, \theta_{j+1}\right), \theta_{i}\right)\right]\left[1+\psi_{1}\left(\theta_{i}\right)\right] \\
{\left[u^{\prime}\left(\ell_{1}\left(\theta_{i}, \theta_{j}\right), \theta_{i-1}\right)-u^{\prime}\left(\ell_{1}\left(\theta_{i}, \theta_{j+1}\right), \theta_{i-1}\right)\right] \psi_{1}\left(\theta_{i-1}\right) .}
\end{gathered}
$$


This expression can be simplified as follows.

$$
\left[v^{\prime}\left(\ell_{1}\left(\theta_{i}, \theta_{j}\right)\right)-v^{\prime}\left(\ell_{1}\left(\theta_{i}, \theta_{j+1}\right)\right)\right] \theta_{i}\left[1+\psi_{1}\left(\theta_{i}\right)\right]<\left[v^{\prime}\left(\ell_{1}\left(\theta_{i}, \theta_{j}\right)\right)-v^{\prime}\left(\ell_{1}\left(\theta_{i}, \theta_{j+1}\right)\right)\right] \theta_{i-1} \psi_{1}\left(\theta_{i-1}\right)
$$

Since $1+\psi_{1}\left(\theta_{i}\right)-\psi_{1}\left(\theta_{i-1}\right)>0$, the expression yields a contradiction for $\ell_{1}\left(\theta_{i}, \theta_{j}\right) \leq \ell_{1}\left(\theta_{i}, \theta_{j+1}\right)$. Hence, $v_{2}\left(\theta_{i}, \theta_{j}\right) \geq v_{2}\left(\theta_{i}, \theta_{j+1}\right)$. Assume now conversely that $v_{2}\left(\theta_{i}, \theta_{j}\right) \geq v_{2}\left(\theta_{i}, \theta_{j+1}\right)$. Then

$$
\begin{aligned}
& u^{\prime}\left(\ell_{1}\left(\theta_{i}, \theta_{j}\right), \theta_{i}\right)\left[1+\psi_{1}\left(\theta_{i}\right)\right]-u^{\prime}\left(\ell_{1}\left(\theta_{i}, \theta_{j}\right), \theta_{i-1}\right) \psi_{1}\left(\theta_{i-1}\right) \\
& \quad \geq u^{\prime}\left(\ell_{1}\left(\theta_{i}, \theta_{j+1}\right), \theta_{i}\right)\left[1+\psi_{1}\left(\theta_{i}\right)\right]-u^{\prime}\left(\ell_{1}\left(\theta_{i}, \theta_{j+1}\right), \theta_{i-1}\right) \psi_{1}\left(\theta_{i-1}\right)
\end{aligned}
$$

and

$$
\left[v^{\prime}\left(\ell_{1}\left(\theta_{i}, \theta_{j}\right)\right)-v^{\prime}\left(\ell_{1}\left(\theta_{i}, \theta_{j+1}\right)\right)\right] \theta_{i}\left[1+\psi_{1}\left(\theta_{i}\right)\right] \geq\left[v^{\prime}\left(\ell_{1}\left(\theta_{i}, \theta_{j}\right)\right)-v^{\prime}\left(\ell_{1}\left(\theta_{i}, \theta_{j+1}\right)\right)\right] \theta_{i-1} \psi_{1}\left(\theta_{i-1}\right),
$$

such that $\ell_{1}\left(\theta_{i}, \theta_{j}\right)>\ell_{1}\left(\theta_{i}, \theta_{j+1}\right)$ cannot be the case and therefore $\ell_{1}\left(\theta_{i}, \theta_{j}\right) \leq \ell_{1}\left(\theta_{i}, \theta_{j+1}\right)$. This proves the third result. The fourth result is proved similarly.

$$
\begin{aligned}
& \text { If } v_{2}\left(\theta_{i}, \theta_{j}\right)>\hat{v} \text { then }-P^{\prime}\left(v_{2}\left(\theta_{i}, \theta_{j}\right)\right)>1 \text { and } \\
& u^{\prime}\left(\ell_{1}\left(\theta_{i}, \theta_{j}\right), \theta_{i}\right)\left[1+\psi_{1}\left(\theta_{i}\right)\right]-u^{\prime}\left(\ell_{1}\left(\theta_{i}, \theta_{j}\right), \theta_{i-1}\right) \psi_{1}\left(\theta_{i-1}\right) \\
& \quad>u^{\prime}\left(\ell_{2}\left(\theta_{i}, \theta_{j}\right), \theta_{j}\right)\left[\tau+\psi_{2}\left(\theta_{j}\right)\right]-u^{\prime}\left(\ell_{2}\left(\theta_{i}, \theta_{j}\right), \theta_{j-1}\right) \psi_{2}\left(\theta_{j-1}\right) \geq u^{\prime}\left(\ell_{2}\left(\theta_{i}, \theta_{j}\right), \theta_{j}\right)\left[\tau+\psi_{2}\left(\theta_{j}\right)-\psi_{2}\left(\theta_{j-1}\right)\right] .
\end{aligned}
$$

Suppose $u^{\prime}\left(\ell_{2}\left(\theta_{i}, \theta_{j}\right), \theta_{j}\right)>\frac{1}{2}$; then

$$
\begin{aligned}
& u^{\prime}\left(\ell_{1}\left(\theta_{i}, \theta_{j}\right), \theta_{i}\right)\left[1+\psi_{1}\left(\theta_{i}\right)\right]-u^{\prime}\left(\ell_{1}\left(\theta_{i}, \theta_{j}\right), \theta_{i-1}\right) \psi_{1}\left(\theta_{i-1}\right) \\
& \quad>\frac{1}{2}\left[\tau+\psi_{2}\left(\theta_{j}\right)-\psi_{2}\left(\theta_{j-1}\right)\right] \\
& \quad=u^{\prime}\left(\ell_{1}\left(\theta_{i}, \theta_{j}\right), \theta_{i}\right)\left[1+\psi_{1}\left(\theta_{i}\right)\right]-u^{\prime}\left(\ell_{1}\left(\theta_{i}, \theta_{j}\right), \theta_{i-1}\right) \psi_{1}\left(\theta_{i-1}\right) .
\end{aligned}
$$

This expression yields a contraction such that $u^{\prime}\left(\ell_{2}\left(\theta_{i}, \theta_{j}\right), \theta_{j}\right) \leq \frac{1}{2}$. The case for local regulator one is proved similarly. This proves the fifth result. 